\title{
A case study on the use of appropriate surrogates for antecedent moisture conditions (AMCs)
}

\author{
G. A. Ali and A. G. Roy \\ Succursale Centre-ville, Montréal (QC) H3C 3J7, Canada \\ Received: 19 May 2010 - Published in Hydrol. Earth Syst. Sci. Discuss.: 4 June 2010 \\ Revised: 29 September 2010 - Accepted: 4 October 2010 - Published: 11 October 2010
}

Chaire de recherche du Canada en dynamique fluviale, Département de géographie, Université de Montréal, C.P. 6128,

\begin{abstract}
While a large number of non-linear hillslope and catchment rainfall-runoff responses have been attributed to the temporal variability in antecedent moisture conditions (AMCs), two problems emerge: (1) the difficulty of measuring AMCs, and (2) the absence of explicit guidelines for the choice of surrogates or proxies for AMCs. This paper aims at determining whether or not multiple surrogates for AMCs should be used in order not to bias our understanding of a system hydrological behaviour. We worked in a small forested catchment, the Hermine, where soil moisture has been measured at 121 different locations at four depths on 16 occasions. Without making any assumption on active processes, we used various linear and nonlinear regression models (i.e. linear, quadratic, cubic, exponential, logarithmic and logistic) to evaluate the point-scale temporal relations between actual soil moisture contents and selected meteorologicalbased surrogates for AMCs. We then mapped the nature of the "best fit" model to identify (1) spatial clusters of soil moisture monitoring sites whose hydrological behaviour was similar, and (2) potential topographic influences on these behaviours. Two conclusions stood out. Firstly, it was shown that the sole reference to AMCs indices traditionally used in catchment hydrology, namely antecedent rainfall amounts summed over periods of seven or ten days, would have led to an incomplete understanding of the Hermine catchment dynamics. Secondly, the relationships between point-scale soil moisture content and surrogates for AMCs were not spatially homogeneous, thus revealing a mosaic of linear and nonlinear catchment "active" and "contributing" sources whose locations were seldom controlled by surface terrain attributes or the topography of a soil-confining layer interface. These
\end{abstract}

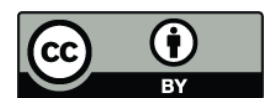

Correspondence to: G. A. Ali

(genevieve.ali@umontreal.ca) results represent a step forward for the Hermine catchment as they point towards depth-specific processes and spatiallyvariable triggering conditions that are not controlled by topography. Further investigations are, however, necessary in order to derive general guidelines for the choice of the best surrogates for AMCs in a catchment.

\section{Introduction}

A large number of non-linear hillslope and catchment rainfall-runoff responses have been documented around the world (e.g. Wipkey and Kirkby, 1978; Sidle et al., 1995; Buttle and Peters, 1997; Buttle et al., 2001; Van Meerveld and McDonnell, 2005; Tromp-Van Meerveld and McDonnell, 2006a; James and Roulet, 2007). Justification for such hydrological responses often lies in the temporal variability in storm size or antecedent moisture conditions (AMCs) (Longobardi et al., 2003; Mishra et al., 2005; James and Roulet, 2009) and the spatial connectivity between source areas. Soil moisture is often described as a major control on catchment response (e.g. Meyles et al., 2003; Western et al., 2004; Western et al., 2005). It is notably used to determine whether a catchment is in a dry and spatially disorganized or in a wet and connected state (Grayson et al., 1997). Catchment AMCs are most often associated with soil moisture contents over a fixed antecedent temporal window that can be defined as:

$W=\left[t_{0}-x, t_{0}\right]$

Where $t_{0}$ is the reference time and $x$ is the amount of time to be subtracted to account for conditions observed before the reference time. Hence, AMCs are used for various purposes, from computing direct surface runoff via the Soil

Published by Copernicus Publications on behalf of the European Geosciences Union. 
Conservation Service Curve Number (SCS-CN) methodology (Mishra et al., 2005) to characterizing favourable conditions for hydrologic connectivity to occur (James and Roulet, 2009).

The determination of a catchment AMCs remains difficult given the strong spatio-temporal heterogeneity of soil moisture across any typical catchment and the relative scarcity of spatially-detailed soil moisture data in comparison to rainfall or streamflow data that are more accessible. Owing to these difficulties, several practical approaches have been proposed to define surrogates or proxies for AMCs. Precipitationbased indices have received the largest attention as rainfall data are often available (Longobardi et al., 2003). We here distinguish between antecedent precipitation $\left(\mathrm{AP}_{x}\right)$ and the antecedent precipitation index $\left(\mathrm{API}_{n}\right) . \mathrm{AP}_{x}$ is simply the cumulative sum of rainfall recorded over any fixed antecedent temporal window as defined in Eq. (1). The $\mathrm{API}_{n}$ as put forward by Kohler and Lindsey (1951) is rather a weighted summation of daily precipitation amounts recorded since the last rainfall as described in Eq. (2):

$\mathrm{API}_{n}=\mathrm{API}_{n-1}+P_{n-1} \cdot \exp (-\alpha \Delta t)$

Where $\Delta t=t_{n}-t_{n-1}$ is the time $(d)$ elapsed between the end of the previous rainfall $P_{n-1}$ and the beginning of the next one $P_{n}$, and $\alpha$ is a parameter equal to the inverse of the characteristic time of soil moisture depletion $\left(d^{-1}\right)$. According to Kohler and Lindsey (1951), precipitation-based indices are universally applicable and yield good results provided that they are used in conjunction with season of the year or temperature. Basin evaporation (Longobardi et al., 2003) and the soil moisture index (SMI), which only includes potential evaporation and other climatic factors in its formulation (Mishra et al., 2005), have also been described as potential proxies for AMCs since they relate to soil moisture depletion. Given the findings that pre-event water can play a substantial role in rainfall-runoff response (e.g. Sklash and Farvolden, 1979; Pearce, 1990; Rice and Hornberger, 1998; Kirchner, 2003) and given the wide availability of streamflow data, the antecedent baseflow index (ABFI) (Mishra et al., 2005) and other measures related to discharge recorded just prior the reference time (Kohler and Lindsey, 1951; Longobardi et al., 2003) have been proposed as surrogates for AMCs. Kohler and Lindsey (1951) have advocated that baseflowderived indices provide reasonably good results in humid and sub-humid regions; however, such as the $\mathrm{API}_{n}$, baseflow indices are strongly dependent upon season of the year and do not necessarily reflect short-term changes in a catchment state. Several authors have emphasized the relative advantage of the ABFI in comparison to antecedent rainfall not only because it reflects both shallow soil moisture and deeper groundwater conditions (Young and Beven, 1994) but also because it does not force the choice of an antecedent temporal window (Mishra et al., 2005) and it is a better predictor of runoff generation (Longobardi et al., 2003). Nonetheless, the ABFI is not often used in the hydrological literature (Mishra et al., 2005), with the exception of a few studies based on water table heights (e.g. James and Roulet, 2009). The number of days since the last rainfall event is another proxy for AMCs that is seldom used in catchment hydrology (Kohler and Lindsey, 1951)

Several questions arise concerning the selection of a proxy for AMCs for a specific catchment. For instance, with regards to antecedent precipitation, what duration of antecedent temporal window should be used? The term "antecedent" is broadly used in the literature and refers to durations from one hour to 30 days. Antecedent temporal windows of seven days (e.g. Woods and Rowe, 1996; Inamdar and Mitchell, 2007; James and Roulet, 2009) and ten days (e.g. Noguchi et al., 2001; Western et al., 2004) are relatively popular in catchment hydrology. Several studies have relied on the dual use of $\mathrm{AP}_{10}$ and $\mathrm{AP}_{30}$ (e.g. Sidle et al., 1995; Vidon et al., 2009). The curve number (CN) method considers rainfall over a 5-day long antecedent temporal window (SCS, 1956), an approach taken up by some hydrological modeling studies (e.g. Brocca et al., 2008). Silveira et al. (2000), however, compared the single use of 5-day antecedent rainfall with the combined use of 15-day antecedent rainfall and potential evaporation and found no significant differences between the two approaches. While working in a semi-arid environment, Frot and van Wesemael (2009) argued that the use of a 48-hour long antecedent temporal window was not appropriate to explain the differences in runoff for events with similar precipitation characteristics and rather chose an antecedent period of 20 days. Within the antecedent window, several scenarios can occur as there may be no rainfall, a single rainfall event, or multiple storms. These events will or will not be accounted for depending on the chosen duration (Salvadori and De Michele, 2006). Thus, Seeger et al. (2004) used a large selection of antecedent windows (i.e. $6 \mathrm{~h}, 24 \mathrm{~h}$, and $3,7,15$ and 21 days) in order to discriminate the effects of short-term AMCs from those of long-term AMCs in a small headwater catchment. The wide range of antecedent temporal windows in the literature is unavoidable as there are no explicit guidelines available to specify the relations between soil moisture content and antecedent rainfall during a specific time period (Mishra et al., 2005). Moreover, the effectiveness of surrogate measures for AMCs may be highly dependent upon climate characteristics and scale of observation. However these issues have yet to be addressed if we are to decide between a universal or a regional proxy for AMCs.

One can also ask if it is reasonable to use a sole measure of AMCs for a given catchment. Several authors (e.g. Cappus, 1960; Betson, 1964; Hewlett and Hibbert, 1967; Dunne and Black, 1970; Aryal et al., 2003; Ambroise, 2004) have shown that storm runoff usually originates from consistent parts of a catchment that often represent a small fraction of the whole topographic drainage area. This has been observed in a range of climatic regimes. Soil moisture is a critical hydrological state variable whose spatiotemporal variation indicates the presence of "active" or "contributing" 
Table 1. Links between surrogate measures for AMCs and hydrologically relevant observations from other studies focusing on the Hermine catchment. " $x \times$ " means that a strong significant correlation was found, " $x$ " means that rather weak correlations were found, and blanks mean that no significant correlations were found.

\begin{tabular}{|c|c|c|c|c|c|c|c|c|c|c|c|}
\hline \multirow[b]{2}{*}{ Hydrologically relevant observations in the Hermine catchment } & \multicolumn{11}{|c|}{ Significant correlations identified with surrogate measures for AMCs } \\
\hline & PET $\mathrm{AP}_{1}$ & $\mathrm{AP}_{2}$ & $\mathrm{AP}_{5}$ & $\mathrm{AP}_{7}$ & $\mathrm{AP}_{10}$ & $\mathrm{AP}_{12}$ & $\mathrm{AP}_{14}$ & DSP & $\mathrm{DSP}_{10}$ & $\mathrm{DSP}_{20}$ & $\mathrm{DSP}_{30}$ \\
\hline $\begin{array}{l}\text { Spatial connectivity of locations whose volumetric soil } \\
\text { moisture content exceeds } 30 \% \\
\text { Source : Ali et al., 2010d }\end{array}$ & & & & $x \times$ & & & & & & & \\
\hline $\begin{array}{l}\text { Development of spatially coherent saturation patches on: } \\
\quad \text { - Areas of } 0.85 \text { to } 1.4 \text { ha at a depth of } 15 \mathrm{~cm} \\
\quad \text { - Areas of } 0.85 \text { ha and less at a depth of } 45 \mathrm{~cm} \\
\text { - Areas of less than } 0.1 \text { ha at soil depths of } 5,15,30 \text { and } 45 \mathrm{~cm} \\
\text { Source : Ali et al., 2010a }\end{array}$ & & & & $x$ & & & $x$ & & & & $\begin{array}{l}x \times \\
x \times\end{array}$ \\
\hline $\begin{array}{l}\text { Relative contribution of geographic sources (e.g. riparian } \\
\text { versus upslope throughfall, organic and mineral soil water) to } \\
\text { streamflow } \\
\text { Source : Ali et al., 2010b }\end{array}$ & & $\times x$ & & $x$ & & & & & & & \\
\hline $\begin{array}{l}\text { Presence of high magnitude and quick timing rainfall-runoff } \\
\text { events } \\
\text { Source : Ali et al., 2010c }\end{array}$ & & & & & $x$ & & & & & & \\
\hline $\begin{array}{l}\text { PET: Mean daily evapotranspiration computed after the temperatur } \\
\text { DSP: Number of days since the last rainfall input } \\
\mathrm{DSP}_{10}, \mathrm{DSP}_{20}, \mathrm{DSP}_{30} \text { : Number of days since the last rainfall inter } \\
\mathrm{AP}_{1}, \mathrm{AP}_{2}, \mathrm{AP}_{5}, \mathrm{AP}_{7}, \mathrm{AP}_{10}, \mathrm{AP}_{12}, \mathrm{AP}_{14} \text { : Cumulative precipitation }\end{array}$ & $\begin{array}{l}\text {-based Hargre } \\
\text { ity exceeding } \\
\text { from } 1,2,5,7\end{array}$ & $0,20 \mathrm{a}$ & 30 & $\begin{array}{l}\text { argrea } \\
\mathrm{m} / \mathrm{d} \\
\text { lays b }\end{array}$ & es, 1975) & & & & & & \\
\hline
\end{tabular}

areas or periods (Ambroise, 2004), and this relates to hydrologic connectivity. Dynamic connectivity of catchment source areas is controlled by the time-changing availability of surface/subsurface storm water, not only in terms of magnitude but also in terms frequency, duration, timing and rate (Bracken and Croke, 2007). Disconnected "active" areas involve water fluxes that do not contribute to the global output at a catchment outlet, while "contributing" areas to catchment response are composed of spatially connected "active" areas. It is generally accepted that catchment structure and morphology are the main factors controlling not only the activation of source areas but also their threshold-driven interconnectivity. From a spatially-distributed point of view, the fact that all catchment areas are not "activated" at the same time may indicate that they are responsive to different antecedent conditions and/or storm events characteristics. Similarly, the non-uniform contribution of source areas to streamflow may point towards different triggering factors. In that context, should multiple proxies for AMCs be used in order not to bias our understanding of a catchment hydrological behaviour?

This paper investigates that specific question. We examine the hydrological behaviour of a 5 ha headwater temperate humid forested system, the Hermine, for which several catchment-wide soil moisture patterns are available. The approach relies on point-scale temporal relations between actual soil moisture content values and selected meteorological-based indices so as to identify the surrogates for AMCs that are best suited to characterize the hydrological behaviour of the system. Such a statistical analysis on data from the Hermine catchment could be particularly useful as previous studies show some inconsistencies in identifying a "universal" AMCs surrogate measure (Table 1). For instance, while characterizing the emergence of spatially coherent saturation patches in the Hermine catchment (Ali et al., 2010a), $\mathrm{DSP}_{30}$ (i.e. number of days elapsed since the last rainfall intensity exceeding $30 \mathrm{~mm} / \mathrm{d}$ ) appeared to be the most influential surrogate measure for AMCs: the smaller the value of $\mathrm{DSP}_{30}$, the more likely the presence of $0.85-1.4$ ha wide saturation patches at a depth of $15 \mathrm{~cm}$. In a paper aiming to identify hydrologically representative connectivity metrics in the Hermine catchment, Ali and Roy (2010d) found that the spatial connectedness of locations whose volumetric soil moisture content exceeded $30 \%$ was rather dependent upon $\mathrm{AP}_{7}$ (i.e. 7-day antecedent precipitation). The relative contribution of sources (i.e. organic versus mineral soil water originating from riparian or upslope areas) to streamflow were also found to be weakly correlated to $\mathrm{AP}_{2}$ and rather strongly correlated to $\mathrm{AP}_{7}$ (Ali et al., 2010b). The occurrence of high magnitude and quick timing rainfall-runoff events was also found to be coincident with 10-day cumulative antecedent precipitation amounts ranging from 24.5 to $40.5 \mathrm{~mm}$ (Ali et al., 2010c). These contrasting results have prompted the current paper where we wish to examine with direct measures whether the use of different AMCs measures lead to different approximations of the Hermine catchment hydrological state. 
(A) Study site localization

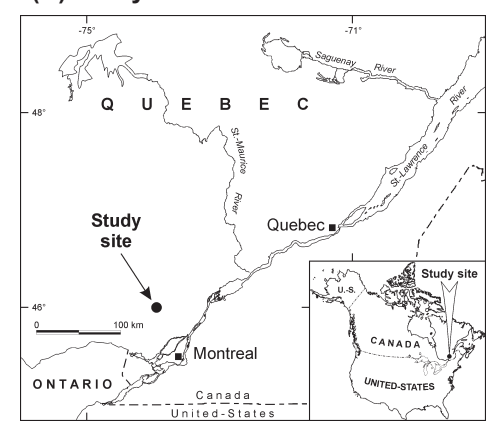

Hermine catchment limits

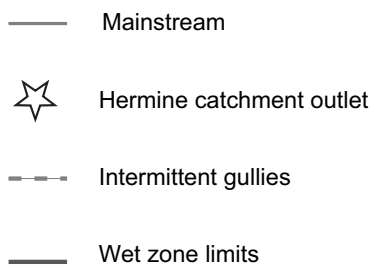

(B) Hermine catchment particular features

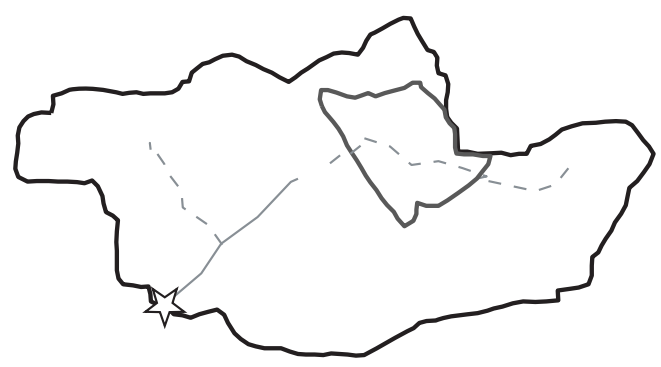

(C) Elevation above the catchment outlet (m)

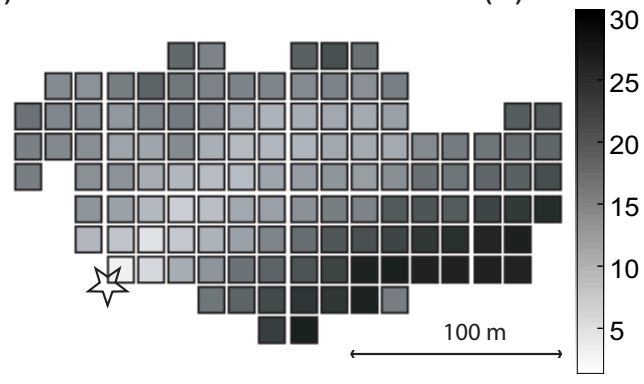

(D) Depth to the confining layer $(\mathrm{cm})$

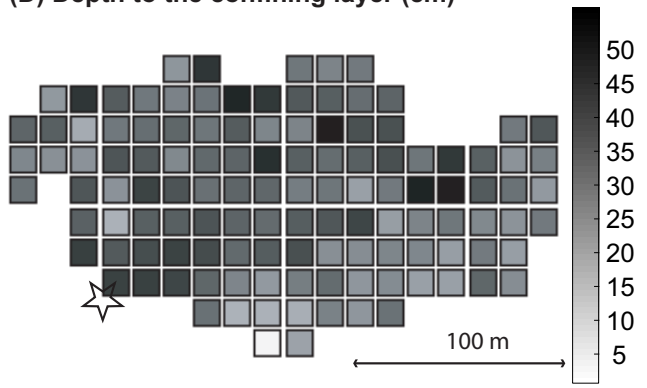

Fig. 1. (A) Location of the Hermine catchment; (B) Hermine catchment particular features; (C) Elevation above the catchment outlet; and (D) Depth to the confining layer for each of the 121 soil moisture sampling locations.

\section{Methods}

\subsection{Hermine catchment}

The Hermine is a 5.1 ha forested catchment located in the Lower Laurentians $80 \mathrm{~km}$ north of Montréal, Québec, Canada (Fig. 1a). The total annual precipitation to the region averages $1150 \mathrm{~mm}( \pm 136 \mathrm{~mm})$ over the last 30 years, of which $30 \%$ falls as snow (Biron et al., 1999). The catchment has a relief of $31 \mathrm{~m}$ and is drained by an ephemeral stream (Fig. 1b). Soils are 1 to $2 \mathrm{~m}$ deep Podzols developed over a bouldery glacial till. The presence of a confining layer at a depth of approximately $75 \mathrm{~cm}$ in the soil restricts root penetration, slows water infiltration and thus enhances the probability of rapid lateral shallow subsurface flow. In wet conditions, catchment-scale soil moisture patterns highly depend upon the asymmetric distribution of thick organic horizons; hydrophilic regions are preferentially located on the northern, steeper hillslopes. Near-surface soil moisture is also influenced by the catchment complex surface microtopography due to fallen tree trunks and boulders at the soil surface. Other particular features of the Hermine include intermittent rills that are activated in very wet conditions (Fig. 1b) and a wet zone located in the upstream part of the valley bottom (Fig. 1b). Forest canopy is dominated by sugar maple and other deciduous tree species. Thus, transpiration is minimal between October and April so that changes in soil moisture and water table in that period are mostly governed by downslope drainage. The interception capacity of the forest canopy, combined with high summer potential evapotranspiration, greatly reduces the likelihood of high runoff except during heavy rainstorms or wet and cool periods. Forest 


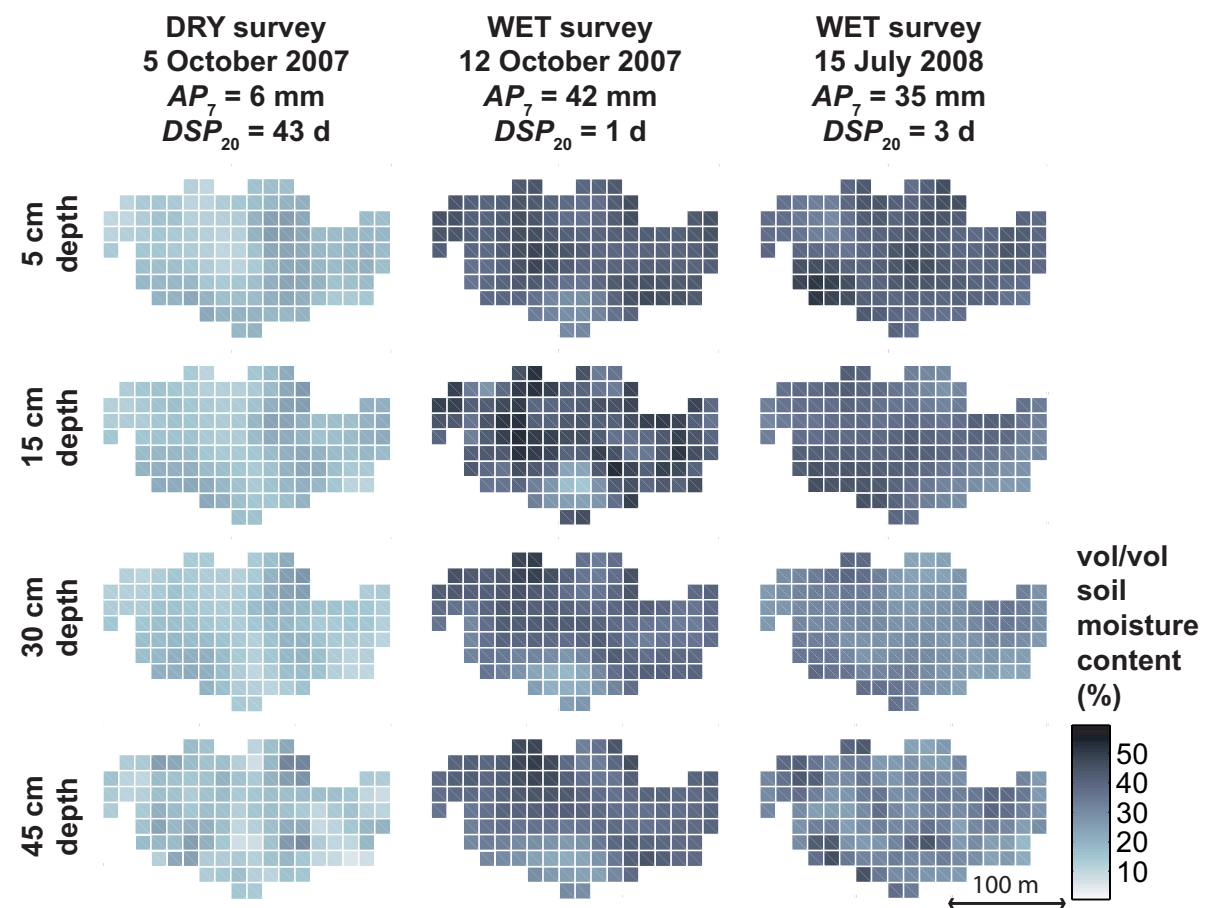

Fig. 2. Sample soil moisture maps obtained after three contrasted surveys in the Hermine catchment.

canopy is, however, variable throughout the catchment, with a lower coverage density in upper parts of the southern slope near the catchment divide for example.

\subsection{Topographic and soil moisture data}

A surface digital elevation model (DEM) of the Hermine was obtained by interpolating 640 elevation points collected in the field. Elevation above the catchment outlet was then extracted for 121 sampling locations defined along a 15 by $15 \mathrm{~m}$ sampling grid in the catchment (Fig. 1c). The depth to the confining layer was measured at 257 points using a small hand auger that was forced vertically to refusal through the soil profile. For each sampling location, three auger to refusal measurements were made in a $1 \mathrm{~m}$ radius and checked for consistency to disregard data that are likely associated with the presence of individual clasts in the soil matrix instead of the targeted confining layer. Data were then interpolated into a subsurface DEM. In order to evaluate topographic influences on the spatial distribution of soil moisture, several secondary terrain attributes were derived from both the surface and the subsurface DEMs: local slope, contributing area and the topographic index (Beven and Kirkby, 1979) were computed using the $\mathrm{D} \infty$ algorithm (Tarboton, 1997), while the multi-resolution valley bottom flatness index (hereafter referred to as the Flatness index) was calculated after Gallant and Dowling (2003). The Flatness index is derived from an elevation map and identifies flat and low regions at a range of scales. Its largest values flag the broadest and flattest low areas in the catchment. The depth to the confining layer was then extracted for each of the 121 sampling locations (Fig. 1d), together with the values of all secondary terrain attributes.

Soil moisture contents at multiple soil depths were surveyed using a portable 40-inch long rod equipped with a capacitance-based probe (AQUATERR Instruments \& Automation) that was manually pushed into the ground to the desirable depth. On 16 occasions between August 2007 and July 2008, volumetric moisture content in the top 5, 15, 30 and $45 \mathrm{~cm}$ of the soil profile was measured on a 0 to $60 \%$ scale along the previously defined 15 by $15 \mathrm{~m}$ sampling grid, for a total of 121 sampling points. Figure 2 illustrates the contrast between surveys conducted at the Hermine, in terms of measured soil moisture patterns for different AMCs and discharges at the catchment outlet (Table 2). In general, saturation patterns tend to be more pronounced at depths of 5 and $15 \mathrm{~cm}$ rather than 30 and $45 \mathrm{~cm}$ (e.g. Fig. 2). Also, in wetter conditions, spatial patterns show higher soil moisture contents on the northern slope of the catchment. The main variability in the patterns is found from sampling time to sampling time, as we observe a strong contrast between dry, transitional and wet conditions (Fig. 2).

\subsection{Surrogates for AMCs and catchment response}

For each of the 16 soil moisture survey dates, 12 temperaturebased, precipitation-based, and soil moisture-based indices (Table 2) were derived in order to assess their potential to 
Table 2. Surrogates for AMCs, catchment macrostate and hydrologic response for 16 soil moisture surveys in the Hermine. See meaning of abbreviations in text.

\begin{tabular}{|c|c|c|c|c|c|c|c|}
\hline Date of survey & $\begin{array}{l}\mathrm{AP}_{1} \\
(\mathrm{~mm})\end{array}$ & $\begin{array}{l}\mathrm{AP}_{2} \\
(\mathrm{~mm})\end{array}$ & $\begin{array}{l}\mathrm{AP}_{5} \\
(\mathrm{~mm})\end{array}$ & $\begin{array}{l}\mathrm{AP}_{7} \\
(\mathrm{~mm})\end{array}$ & $\begin{array}{l}\mathrm{AP}_{10} \\
(\mathrm{~mm})\end{array}$ & $\begin{array}{l}\mathrm{AP}_{12} \\
(\mathrm{~mm})\end{array}$ & $\begin{array}{l}\mathrm{AP}_{14} \\
(\mathrm{~mm})\end{array}$ \\
\hline 6 August 2007 & 0 & 0 & 4 & 4 & 36 & 36 & 36 \\
\hline 13 August 2007 & 12 & 12 & 17 & 44 & 44 & 48 & 48 \\
\hline 7 September 2007 & 8 & 8 & 8 & 8 & 8 & 22 & 44 \\
\hline 14 September 2007 & 0 & 0 & 14 & 14 & 15 & 22 & 22 \\
\hline 21 September 2007 & 0 & 0 & 0 & 18 & 22 & 32 & 32 \\
\hline 28 September 2007 & 4 & 4 & 4 & 4 & 4 & 4 & 22 \\
\hline 5 October 2007 & 0 & 0 & 0 & 6 & 10 & 10 & 10 \\
\hline 12 October 2007 & 25 & 25 & 40 & 42 & 42 & 42 & 48 \\
\hline 26 October 2007 & 0 & 0 & 15 & 43 & 43 & 43 & 67 \\
\hline 2 November 2007 & 3 & 3 & 3 & 33 & 36 & 48 & 76 \\
\hline 9 November 2007 & 0 & 0 & 17 & 17 & 20 & 20 & 50 \\
\hline 20 May 2008 & 10 & 20 & 36 & 39 & 39 & 39 & 54 \\
\hline 2 June 2008 & 2 & 21 & 27 & 29 & 29 & 49 & 61 \\
\hline 17 June 2008 & 13 & 14 & 14 & 29 & 29 & 37 & 37 \\
\hline 15 July 2008 & 2 & 3 & 19 & 43 & 43 & 54 & 59 \\
\hline 21 July 2008 & 0 & 0 & 33 & 35 & 42 & 73 & 75 \\
\hline Date of survey & $\begin{array}{l}\text { DSP } \\
\text { (d) }\end{array}$ & $\begin{array}{l}\mathrm{DSP}_{10} \\
\text { (d) }\end{array}$ & $\begin{array}{c}\mathrm{DSP}_{20} \\
\text { (d) }\end{array}$ & $\begin{array}{c}\mathrm{DSP}_{30} \\
\text { (d) }\end{array}$ & $\begin{array}{c}\text { PET } \\
(\mathrm{mm} / \mathrm{d})\end{array}$ & $\begin{array}{c}\theta_{\text {mean }} \\
(\% \text { vol })\end{array}$ & $\begin{array}{c}Q_{\mathrm{obs}} \\
(\mathrm{mm} / \mathrm{d})\end{array}$ \\
\hline 6 August 2007 & 0 & 0 & 0 & 9 & 2.61 & 33.8 & 0.66 \\
\hline 13 August 2007 & 0 & 1 & 7 & 16 & 2.58 & 23.3 & 0.22 \\
\hline 7 September 2007 & 1 & 9 & 15 & 41 & 3.15 & 27.0 & 0.05 \\
\hline 14 September 2007 & 0 & 3 & 22 & 48 & 2.19 & 29.0 & 0.07 \\
\hline 21 September 2007 & 6 & 6 & 29 & 55 & 2.07 & 27.7 & 0.06 \\
\hline 28 September 2007 & 0 & 13 & 36 & 62 & 1.73 & 27.9 & 0.10 \\
\hline 5 October 2007 & 7 & 20 & 43 & 69 & 2.40 & 17.3 & 0.09 \\
\hline 12 October 2007 & 0 & 0 & 1 & 76 & 1.49 & 39.6 & 5.87 \\
\hline 26 October 2007 & 3 & 3 & 7 & 90 & 1.33 & 23.1 & 0.91 \\
\hline 2 November 2007 & 1 & 6 & 6 & 6 & 1.23 & 21.5 & 1.52 \\
\hline 9 November 2007 & 3 & 3 & 13 & 13 & 0.86 & 21.1 & 1.71 \\
\hline 20 May 2008 & 0 & 2 & 22 & 141 & 1.87 & 34.4 & 1.80 \\
\hline 2 June 2008 & 0 & 2 & 35 & 154 & 2.89 & 30.0 & 0.83 \\
\hline 17 June 2008 & 0 & 1 & 50 & 169 & 2.37 & 32.2 & 0.52 \\
\hline 15 July 2008 & 1 & 3 & 6 & 197 & 2.51 & 31.5 & 0.42 \\
\hline 21 July 2008 & 0 & 0 & 3 & 203 & 2.44 & 35.2 & 0.78 \\
\hline
\end{tabular}

serve as surrogates for antecedent conditions estimated from the soil moisture measurements. Mean daily potential evapotranspiration (PET) was computed on a diurnal timescale after the temperature-based Hargreaves formula (Hargreaves, 1975). A first group of seven precipitation-based indices were used to capture the amount of rainfall added to the system over a given period $x\left(\mathrm{AP}_{x}\right)$ prior to the time of interest. $\mathrm{AP}_{1}, \mathrm{AP}_{2}, \mathrm{AP}_{5}, \mathrm{AP}_{7}, \mathrm{AP}_{10}, \mathrm{AP}_{10}$ and $\mathrm{AP}_{14}$ were, respectively calculated as the cumulative rainfall over the $1,2,5$, $7,10,12$ and 14 days prior to the survey. A second group of precipitation-based indices were used to reflect the time distribution of the antecedent water inputs. DSP (i.e. days since precipitation) was computed as the number of days elapsed since the last recording at the rain gage, while the $\mathrm{DSP}_{10}$,
$\mathrm{DSP}_{20}$ and $\mathrm{DSP}_{30}$ indices were computed as the number of days elapsed since the last rainfall intensity exceeding 10 , 20 and $30 \mathrm{~mm} \mathrm{~d}^{-1}$, respectively. These indices were especially chosen for their computational simplicity and the absence of mathematical parameters (e.g. soil moisture depletion time) to be estimated. The ability of the survey mean soil moisture content ( $\theta_{\text {mean }}$, computed over all depths and sampling points) to represent the catchment macrostate was also evaluated. Lastly, catchment discharges recorded on survey dates (current-day discharges, hereafter referred as $Q_{\mathrm{obs}}$ ) were used to portray the integrated hydrological response at the catchment outlet. 


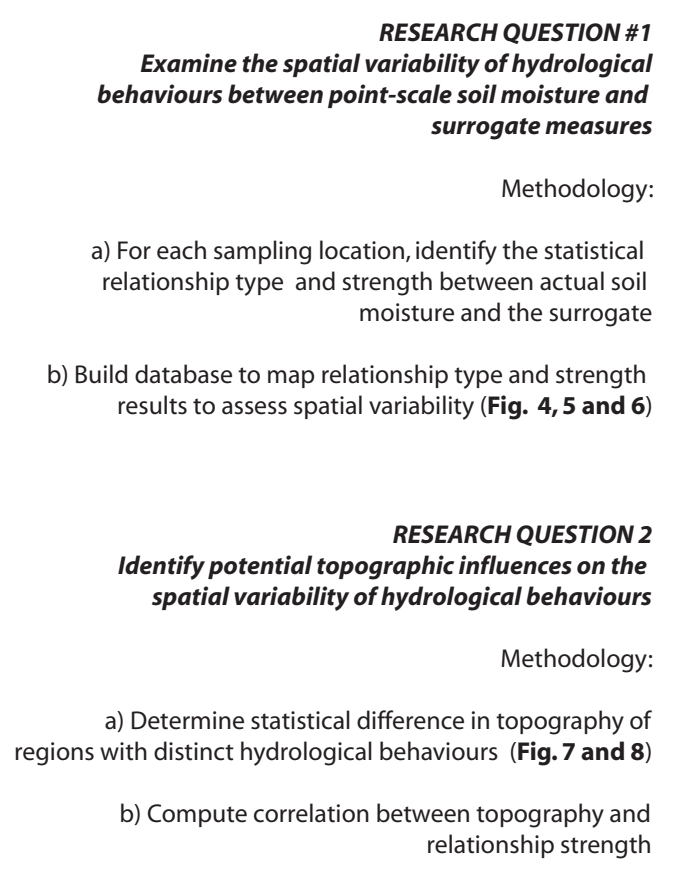

RESEARCH QUESTION \# 1 Examine the spatial variability of hydrological le soil moisture and Methodology:

a) For each sampling location, identify the statistical relationship type and strength between actual soil

Build database to map relationship type and strength results to assess spatial variability (Fig. 4, 5 and 6)

Methodology:

with distinct hydrological behaviours (Fig. 7 and 8 )

relationship strength

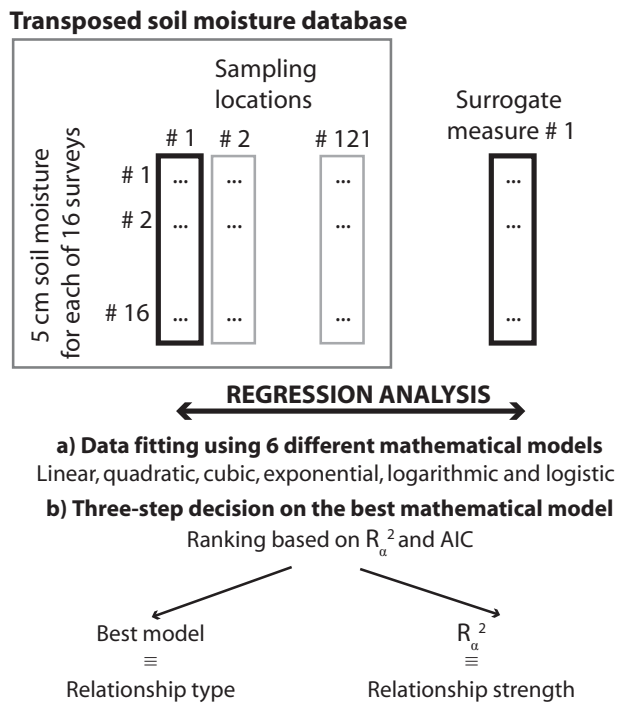

Results from STEP 1 for Surrogate measure \# 1

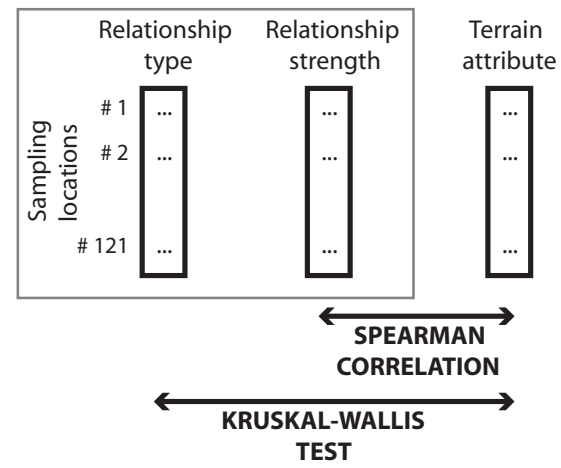

Fig. 3. Methodological approach used in this paper. $R_{\alpha}^{2}$ refers to the adjusted coefficient of determination while AIC refers to the Akaike Information Criterion.

\subsection{Data analysis}

Our methodology intended to answer two research questions (Fig. 3). Firstly, we aimed to determine the nature and the strength of the relationships between point-scale soil moisture (i.e. soil moisture measured at each sampling point) and each of the AMCs and catchment response surrogates previously described. We hypothesized that the identified relationships would illustrate the variety of point-scale hydrologic behaviours that can be encountered within the Hermine catchment. Secondly, we examined the spatial organization of the nature and the strength of these point-scale relationships to link them with possible topographic controls.

For the determination of point-scale relationships, data cases were soil moisture survey dates $(n=16)$. When the aim was to evaluate the ability of AMCs measures to describe soil moisture patterns, the independent variable was the chosen surrogate for AMCs and the dependent variable was the depth-specific, point-scale soil moisture content. In order to assess the potential of $\theta_{\text {mean }}$ to represent the Her- mine catchment macrostate, we rather considered $\theta_{\text {mean }}$ to be an independent variable while point-scale soil moisture was the dependent one. Lastly, in order to identify catchment areas that might contribute to streamflow discharge, the statistical procedure detailed below was also applied using point-scale soil moisture as the dependent variable and $Q_{\mathrm{obs}}$ as the independent one. No postulate could be made on the form of the relationship between the dependent and the independent variables since no such exercise has been done before. Six regression models (i.e. linear, quadratic, cubic, exponential, logarithmic and logistic), which represent six different types of possible relationships, were fitted to the data and compared so as to select the one with the best fit. Model equations can be written as follows:

Linear model

$Y=a \cdot X+b$

Quadratic (monotonic increasing) model 
Cubic (monotonic increasing) model

$Y=a \cdot X^{3}+b \cdot X^{2}+c \cdot X+d$

Exponential model

$Y=a \cdot e^{b X}$

Logarithmic model

$Y=a+b \cdot \ln (X)$

Logistic model

$Y=\frac{c}{1+a \cdot e^{-b X}}$

Where $Y$ is the dependent variable, $X$ is the independent variable, and $a, b, c$ and $d$ are model parameters. There was no physical basis for the choice of the six mathematical models; the aim was rather to explore the dataset using different models with various degrees of complexity. In each case, a least squares-like regression method was used for all models, which means that the fitting of each model to the data had to minimize the squared differences between observed and predicted values. Selection of the best mathematical model among the six tested was then performed in three steps.

First, the adjusted coefficient of determination $\left(R_{\alpha}^{2}\right)$ was used to discard any model that would only explain a small proportion of the variance in the data. Throughout this paper, we refer to $R$-square $\left(R^{2}\right)$ as the proportion of variance in the dependent variable that is explained by the chosen regression model. It can be computed for any linear or nonlinear model:

$R^{2}=1-\frac{\mathrm{RSS}}{\mathrm{TSS}}$

where SS refers to a sum of squares. TSS is the total amount of variability in the dependent variable while residual RSS is the amount of variability that still cannot be accounted for after the regression model is fitted to the data. Given that the value of $R^{2}$ often increases when a nonlinear model is used instead of a linear relationship, the use of the $R_{\alpha}^{2}$ is more adequate in the context of multiple models evaluation and comparison as it assesses the goodness of fit while taking into consideration the numbers of degrees of freedom of the numerator and the denominator of $R^{2}$ (Legendre and Legendre, 1998):

$R_{\alpha}^{2}=1-\left(1-R^{2}\right)\left(\frac{N-1}{N-k-1}\right)$

where $N$ is the sample size and $k$ is the number of parameters. Hence, $R_{\alpha}^{2}$ "penalizes" models bearing a large number of parameters. For the current analysis, if all six models failed to produce an $R_{\alpha}^{2}$ value exceeding 0.3 , then the relationship between point-scale soil moisture and the surrogate measure being evaluated was labelled as "not significant". Otherwise, only the models with an $R_{\alpha}^{2}$ exceeding 0.3 were kept for further consideration towards choosing the best fitting model.

As a second step in the best model selection, the models with an $R_{\alpha}^{2}$ exceeding 0.3 were ranked according to their corrected Akaike Information Criterion value. The Akaike Information Criterion or AIC (Akaike, 1974) is also a measure of the goodness of fit of a mathematical model but on the contrary to the $R_{\alpha}^{2}$, it is not grounded in the statistical theory of hypothesis testing but rather in the information theory. The AIC estimates the Kullback-Leibler information loss by approximating the observed data with the fitted model (details regarding model selection using information theory can be found in Burnham and Anderson, 2002). The fit of any regression model to any dataset can be summarized by the Akaike Information Criterion (AIC) defined by the equation:

$\mathrm{AIC}=N \cdot \ln \left(\frac{\mathrm{RSS}}{N}\right)+2 K$

where $N$ is the number of data points and $K$ is the number of parameters fit by the regression plus one. The definition of I as the number of parameters plus one is justified by the fact that the regression is "estimating" not only the values of the parameters but also the sum of squares. It is worth noting that the computation equation of the AIC consists of two additive terms, namely one term representing the lack of model fit to the data and another term related to the number of parameters; hence, the AIC can be seen as a measure of both the accuracy and the complexity of the chosen model. In cases where $N / K<40$ as in this study, a second order corrected $\mathrm{AIC}$, hereafter referred to as $\mathrm{AIC}_{c}$, is used:

$\mathrm{AIC}_{c}=\mathrm{AIC}+\frac{2 K(K+1)}{N-K-1}$

When comparing several mathematical models, it is the one with the lowest $\mathrm{AIC}_{c}$ that is the best or that is most likely to be correct. Hence, in this study, mathematical models with an $R_{\alpha}^{2}$ exceeding 0.3 were ranked by sorting their associated $\mathrm{AIC}_{c}$ scores in ascending order, and the top-ranked model chosen as the best one.

The third and last step in the best model selection process consisted in confirming the choice made at the end of step 2. Indeed, if the $\mathrm{AIC}_{c}$ scores between the top two-ranked models are very close, there is not much evidence to choose one model over the other. We therefore used the following equation to compute the probability that the top ranked model is indeed the best one:

$w=\frac{e^{-0.5\left(\mathrm{AIC}_{c_{2}}-\mathrm{AIC}_{c_{1}}\right)}}{1+e^{-0.5\left(\mathrm{AIC}_{c_{2}}-\mathrm{AIC}_{c_{1}}\right)}}$

This probability can thus be seen as an uncertainty measure as it expresses the likelihood that the top-ranked model is the best among the set of models being evaluated.

The possible influence of catchment topography, both surface and subsurface, was studied with regards not only to the 


\section{$5 \mathrm{~cm}$ depth}
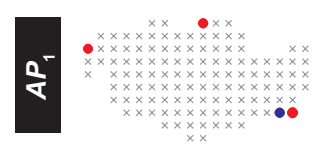

-
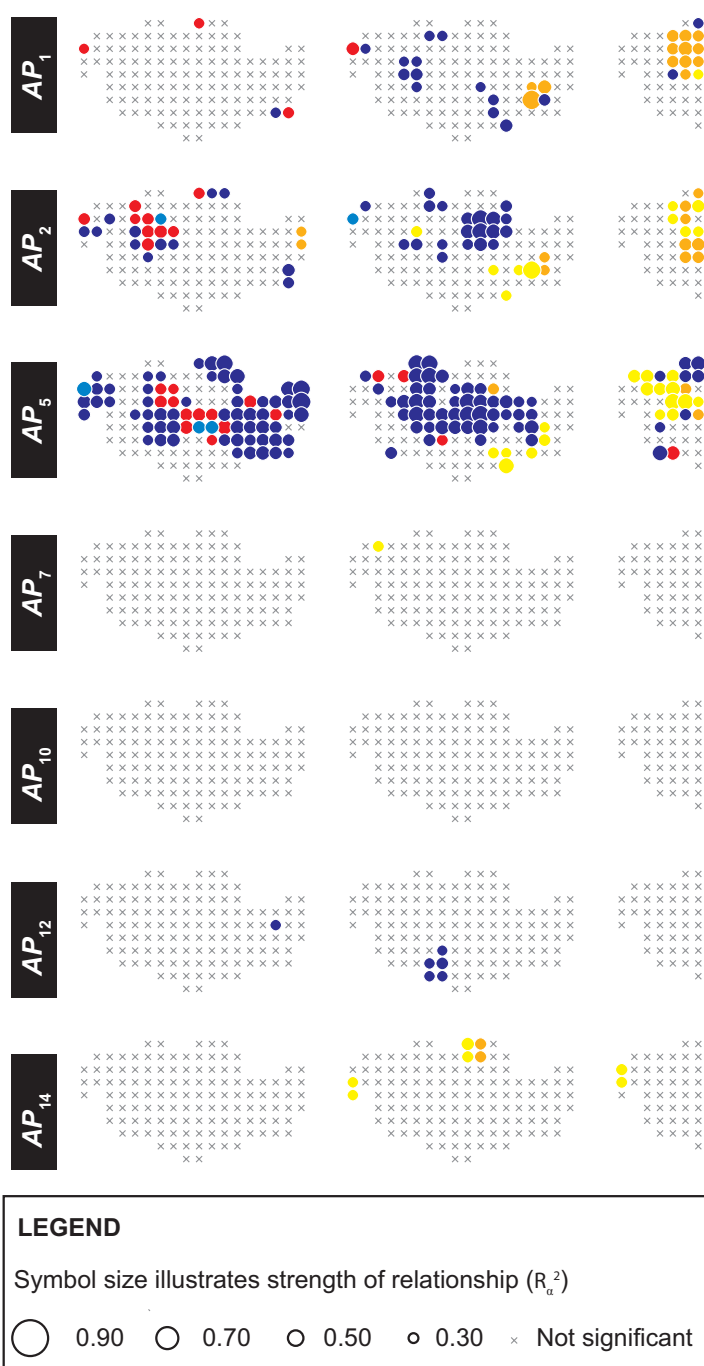

\section{$30 \mathrm{~cm}$ depth}
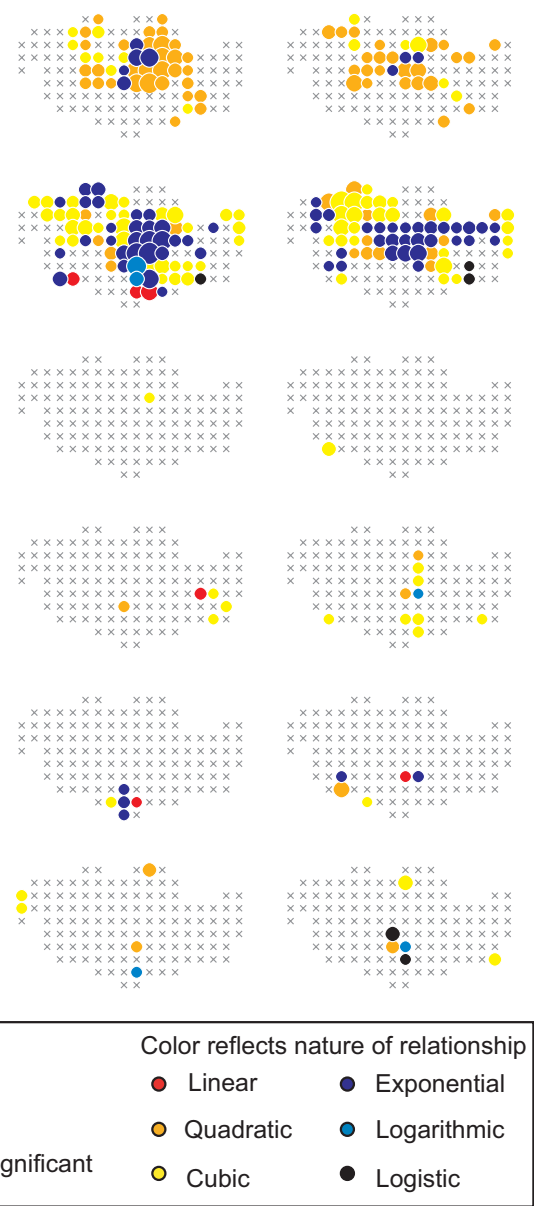

Fig. 4. Nature and strength of the relationships between point-scale soil moisture content and $\mathrm{AP}_{x}$ indices $(x=1,2,5,7,10,12$ or 14 days) used as surrogates for AMCs. $R_{\alpha}^{2}$ refers to the adjusted $R$-square.

nature (e.g. linear versus quadratic, versus cubic, etc.) but also to the strength of the point-scale relationships between actual soil moisture and surrogate measures. Nonparametric Kruskal-Wallis tests were run to assess whether the different types of point-scale relationships were spatially associated with specific topographic properties. The Kruskal-Wallis test is identical to one-way analysis of variance except that the data are replaced by their ranks. Hence, it is used to compare samples from three or more groups. The null hypothesis states that all group medians are equal, while the alternative hypothesis states that at least one group median is different from the others. In this study, each mathematical model is a group and we compare the topography underlying the locations subjected to different relationships between pointscale relationships between actual soil moisture and surro- gate measures. When the p-value associated with the statistical test is less than 0.05 , we reject the null hypothesis and suggest that the differences in relationship types can be explained by topography. Spearman correlation coefficients were also computed between the strength of the point-scale relationships (i.e. $R_{\alpha}^{2}$ values) and the values of the terrain attributes.

\section{Results}

\subsection{Point-scale relationships}

Each symbol in Figs. 4 and 5 illustrates the best mathematical model between point-scale soil moisture content and a given surrogate measure. Following the three-step procedure 


\section{$5 \mathrm{~cm}$ depth}

紧

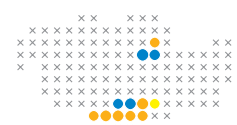

1

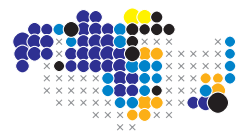

$\frac{5^{\circ}}{2}$
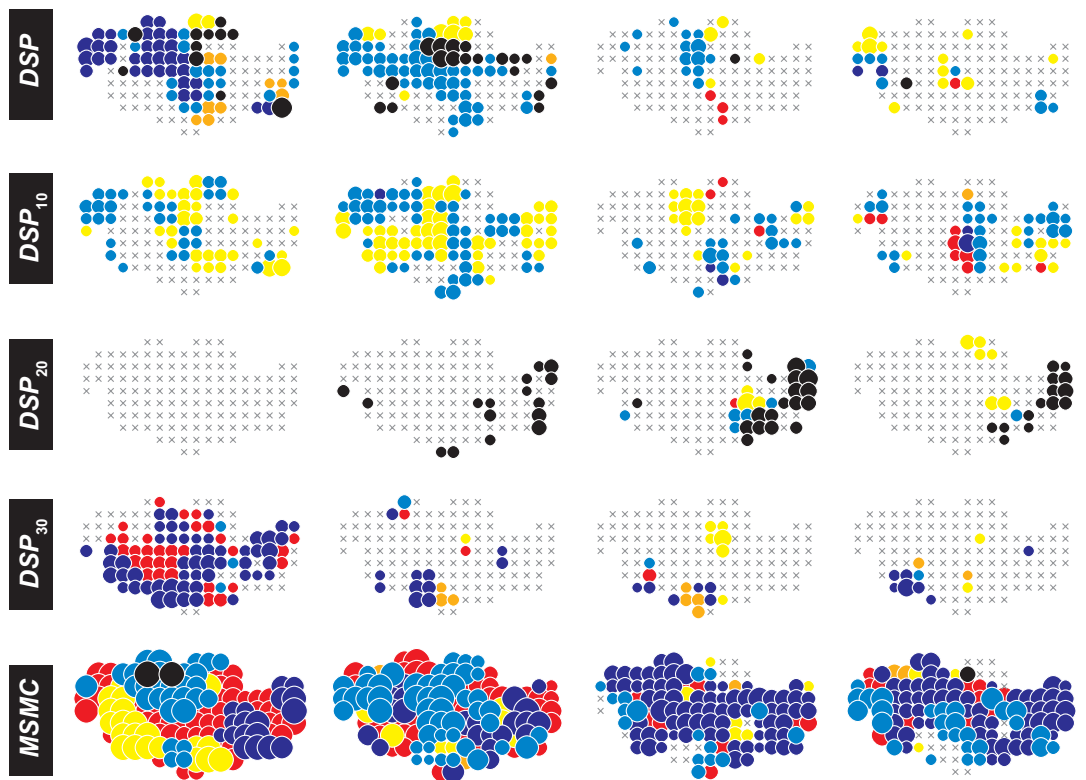

LEGEND

Symbol size illustrates strength of relationship $\left(\mathrm{R}_{u}{ }^{2}\right)$

0.90

○ 0.70

○ 0.50

$\circ 0.30$

Not significant

\section{$30 \mathrm{~cm}$ depth $\quad 45 \mathrm{~cm}$ depth}
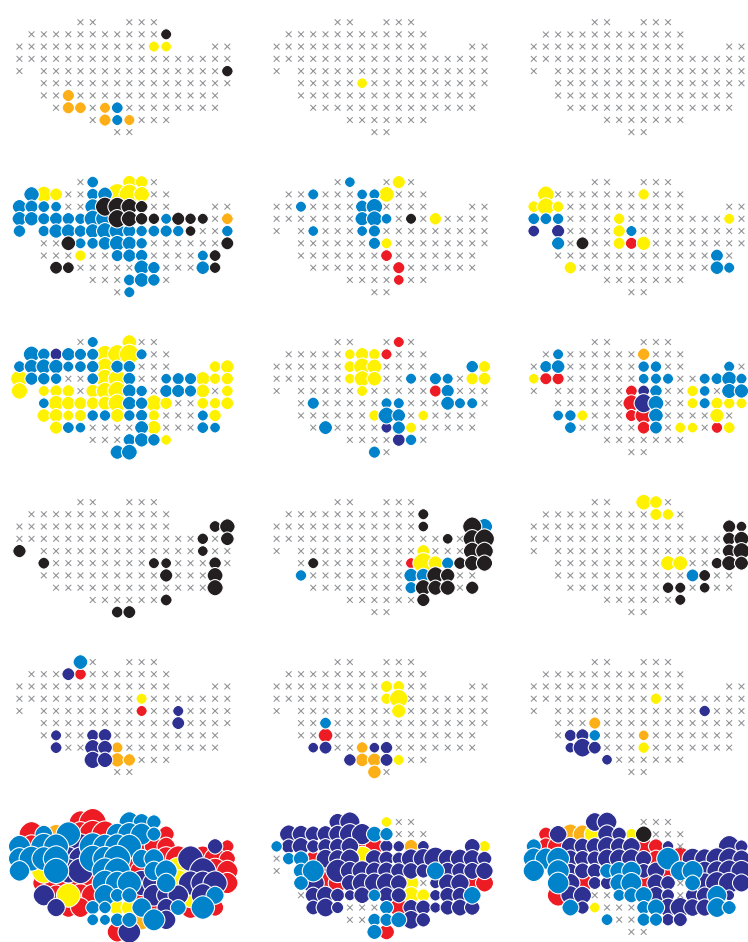

Color reflects nature of relationship

- Linear - Exponential

- Quadratic o Logarithmic

○ Cubic - Logistic

Fig. 5. Nature and strength of the relationships between point-scale soil moisture content, PET, DSP and DSP $x$ indices $(x=0,10,20$ or $30 \mathrm{~mm} / \mathrm{d}$ ) used as surrogates for AMCs, and $\theta_{\text {mean }}$ used as a surrogate for the Hermine catchment macro-state. $R_{\alpha}^{2}$ refers to the adjusted $R$-square.

previously described, it appears that on average, the models chosen as the best ones had a probability of being correct ranging from 52 to $100 \%$ (Table 3). Figures 4 and 5 illustrate the spatial heterogeneity in the Hermine when it comes to the relation between point-scale actual soil moisture measurements and any catchment-wide, meteorological-based proxy for AMCs. Figures 4 and 5 also show that the spatial patterns are highly dependent not only upon the chosen surrogate for AMCs but also upon the soil depth considered. For instance, only $10 \%$ of the soil moisture sampling sites at a $5 \mathrm{~cm}$ depth are related to PET (Fig. 5). The best regression model for that relationship is a quadratic one; however $R_{\alpha}^{2}$ values do not exceed 0.38. A similar result is obtained at a depth of $15 \mathrm{~cm}$ where only $10 \%$ of the sampling locations are related to PET, and that proportion drops to zero when depths of 30 or $45 \mathrm{~cm}$ are considered.

For precipitation-based indices computed from cumulative rainfall, especially $\mathrm{AP}_{1}, \mathrm{AP}_{2}$ and $\mathrm{AP}_{5}$, linear relationships are mostly present at a $5 \mathrm{~cm}$ depth while nonlinear relationships tend to dominate from a depth of $15 \mathrm{~cm}$ and below
(Fig. 4). Regarding the point-scale relationships between soil moisture and $\mathrm{AP}_{1}\left(\right.$ or $\left.\mathrm{AP}_{2}\right)$, exponential models dominate at the $15 \mathrm{~cm}$ depth while quadratic models rather dominate at the 30 and $45 \mathrm{~cm}$ depths. It is at a depth of $30 \mathrm{~cm}$ that most locations with a significant relationship between $\mathrm{AP}_{1}$ (or $\mathrm{AP}_{2}$ ) and soil moisture content measurements were found, with a mean relationship strength (i.e. $R_{\alpha}^{2}$ ) of 0.4. With $\mathrm{AP}_{5}$, linear and exponential models are mostly present at the 5 and $15 \mathrm{~cm}$ depths while cubic and quadratic relationships make up most of the patterns at depths of 30 and $45 \mathrm{~cm}$. Significant relations between $\mathrm{AP}_{5}$ and point-scale soil moisture content measurements are the strongest $\left(0.30 \leq R_{\alpha}^{2} \leq 0.73\right)$ and the most widespread over the Hermine catchment area. On the contrary, patterns associated with $\mathrm{AP}_{7}, \mathrm{AP}_{10}$ and $\mathrm{AP}_{14}$ show very few, if any, significant relations. Relationships between $\mathrm{AP}_{12}$ and point-scale soil moisture content measurements are of interest not because of their magnitude but rather because they are only made out from four to six locations confined to the catchment southern slope (Fig. 4), which is opposite to the patterns associated with $\mathrm{AP}_{1}, \mathrm{AP}_{2}$ and $\mathrm{AP}_{5}$. Indeed, 


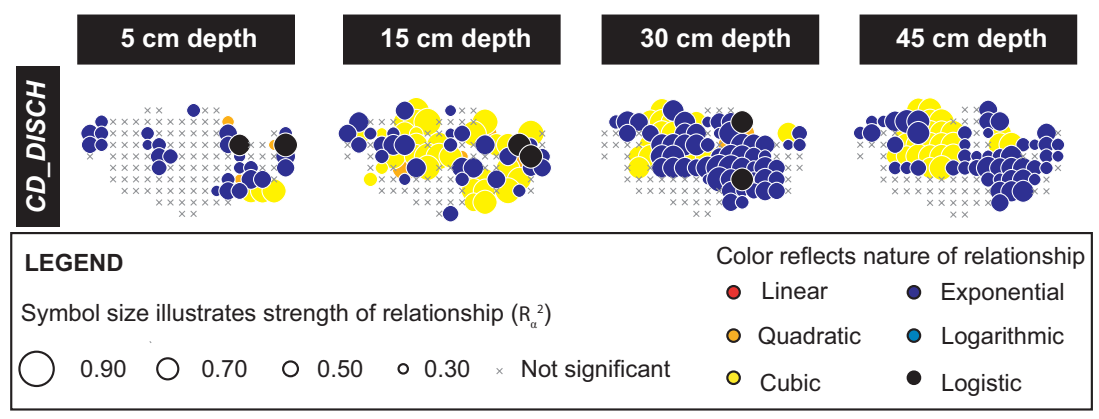

Fig. 6. Nature and strength of the relationships between point-scale soil moisture content and $Q_{\text {obs }}$ used as a surrogate for the Hermine catchment response. $R_{\alpha}^{2}$ refers to the adjusted $R$-square.

Table 3. Catchment-wide average of Akaike weights or probabilities associated with the best mathematical model chosen to illustrate the relationships between point-scale soil moisture content and surrogate measures.

\begin{tabular}{llcccc}
\hline & & \multicolumn{4}{c}{ Point-scale soil moisture } \\
\cline { 3 - 6 } Surrogate & RAIN & 0.76 & 0.76 & 0.66 & 0.69 \\
measures & $\mathrm{PET}$ & 0.83 & 0.83 & $*$ & $*$ \\
& $\mathrm{AP}_{1}$ & 0.65 & 0.65 & 0.88 & 0.89 \\
& $\mathrm{AP}_{2}$ & 0.56 & 0.56 & 0.83 & 0.85 \\
& $\mathrm{AP}_{5}$ & 0.57 & 0.57 & 0.62 & 0.66 \\
& $\mathrm{AP}_{7}$ & $*$ & 1.00 & 1.00 & 1.00 \\
$\mathrm{AP}_{10}$ & $*$ & $*$ & 0.59 & 1.00 \\
& $\mathrm{AP}_{12}$ & 0.79 & 0.79 & 0.56 & 0.57 \\
& $\mathrm{AP}_{14}$ & $*$ & 0.70 & 0.83 & 0.87 \\
& $\mathrm{DSP}$ & 0.55 & 0.55 & 0.54 & 0.52 \\
& $\mathrm{DSP}_{10}$ & 0.65 & 0.65 & 0.56 & 0.57 \\
$\mathrm{DSP}_{20}$ & $*$ & 1.00 & 0.71 & 0.74 \\
$\mathrm{DSP}_{30}$ & 0.59 & 0.59 & 0.56 & 0.60 \\
$Q_{\text {obs }}$ & 0.86 & 0.86 & 0.92 & 0.95 \\
$\theta_{\text {mean }}$ & 0.62 & 0.62 & 0.63 & 0.61 \\
\hline
\end{tabular}

with $\mathrm{AP}_{12}$, the small cluster of locations subjected to significant relationships on the southern slope is opposed to the widespread presence of significant models on the northern hillslope and in the catchment upstream area when $\mathrm{AP}_{1}, \mathrm{AP}_{2}$ or $\mathrm{AP}_{5}$ are used as surrogates for AMCs (Fig. 4).

Spatial patterns of point-scale relationships were also different depending upon the chosen rainfall intensity-based measure of AMCs. Figure 5 shows that for all soil depths, a large proportion of sampling locations are significantly, yet weakly related to DSP at depths of 5 and $15 \mathrm{~cm}$ (mean $R_{\alpha}^{2}$ of 0.42 ). Exponential relationships between ${ }^{\mathrm{DSP}}$ and soil moisture dominate at $5 \mathrm{~cm}$ while logarithmic relationships rather dominate at $15 \mathrm{~cm}$. With $\mathrm{DSP}_{10}$, cubic and logarithmic relationships were present at depths of 5 and $15 \mathrm{~cm}$. With $\mathrm{DSP}_{20}$, significant logistic models were found particularly at the 30 and $45 \mathrm{~cm}$ depths in the headwater, upslope portion of the study area near the catchment divide (Fig. 5). As for significant relationships between $\mathrm{DSP}_{30}$ and point-scale soil moisture content measurements, they were the most obvious at the $5 \mathrm{~cm}$ depth with a mix of linear and exponential regression models.

For almost all sampling locations at all depths, significant relationships between soil moisture content measurements and $\theta_{\text {mean }}$ are found $\left(0.32 \leq R_{\alpha}^{2} \leq 0.91\right)$. The vast majority of these relationships are linear, quadratic, cubic and exponential (Fig. 5). The proportion of sampling locations sharing nonlinear relationships with $\theta_{\text {mean }}$ is $58 \%$ at a depth of $5 \mathrm{~cm}$ and reaches $66 \%$ at a depth of $15 \mathrm{~cm}$ and even $90 \%$ at depths of 30 and $45 \mathrm{~cm}$. As far as the variable $Q_{\text {obs }}$ is concerned, the presence of statistically significant relations is highly dependent upon soil depth (Fig. 6). At the $5 \mathrm{~cm}$ depth, very few locations are characterized by a significant relationship between point-scale soil moisture and $Q_{\text {obs }}$. At the three other soil depths investigated, exponential and cubic models dominate while the strength of the relationships is greater than at $5 \mathrm{~cm}$ (mean $R_{\alpha}^{2}$ value of 0.62 , maximum $R_{\alpha}^{2}$ ranging from 0.80 to 0.90 from the $15 \mathrm{~cm}$ depth below). At 30 and $45 \mathrm{~cm}$, the spatial patterns of significant relationships resemble the spatial patterns obtained with $\mathrm{AP}_{1}, \mathrm{AP}_{2}$ and $\mathrm{AP}_{5}$.

The relationships between $\theta_{\text {mean }}$ and surrogate measures for AMCs and between $\theta_{\text {mean }}$ and $Q_{\text {obs }}$ were also examined (Fig. 7) and compared to the point-scale relationships illustrated in Figs. 4, 5 and 6. $\theta_{\text {mean }}$ was only found to be correlated with $\mathrm{AP}_{5}, \mathrm{DSP}$ and $\mathrm{DSP}_{10}$ given weak $R_{\alpha}^{2}$ values $(\leq 0.4)$. Among the six mathematical models tested (e.g. linear, quadratic, cubic, exponential, logarithmic and logistic), the exponential one was best suited to explain the relationship between $Q_{\text {obs }}$ and $\mathrm{AP}_{5}$ while $Q_{\mathrm{obs}}$ and DSP and $\mathrm{DSP}_{10}$ were rather linked in a logarithmic manner. The exponential (or logarithmic) model was also the most widespread when relationships between point-scale soil moisture contents and $\mathrm{AP}_{5}$ (or DSP and DSP 10 ) were examined (Figs. 4 and 5). However, the use of $\theta_{\text {mean }}$ rather than point-scale soil moisture measurements prevented us from knowing that the strengths of the relationships were highly variable in space and were often associated with $R_{\alpha}^{2}$ values exceeding 0.4 

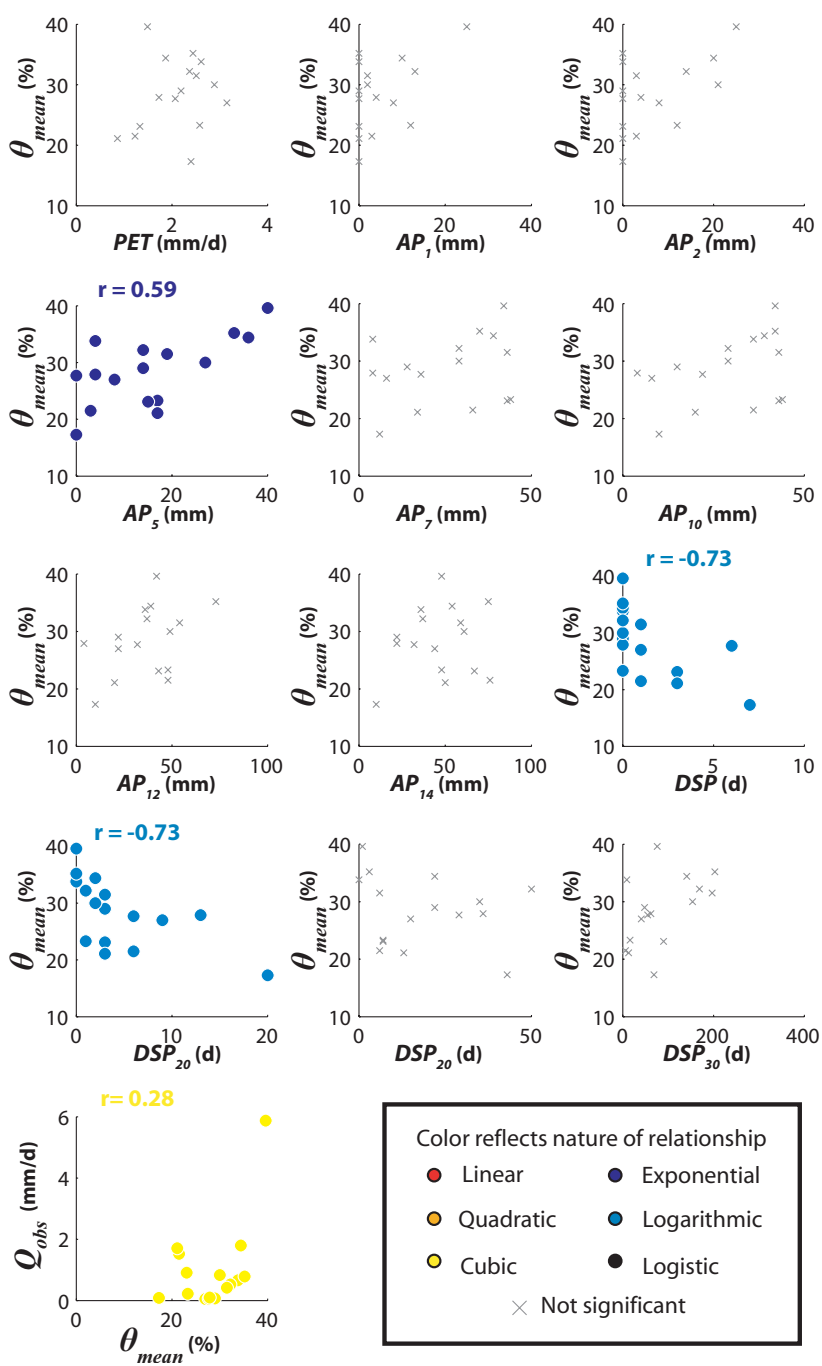

Fig. 7. Relationships between the mean soil moisture content $\left(\theta_{\text {mean }}\right)$ and surrogate measures for AMCs and catchment response. " $r$ " refers to the Spearman correlation coefficient.

(Figs. 4 and 5). A strong $\left(R_{\alpha}^{2}=0.88\right)$ cubic relationship was found between $\theta_{\text {mean }}$ and $Q_{\text {obs }}$ (Fig. 7); this was a surprising given Fig. 6 showing that exponential relationships dominate between point-scale soil moisture contents and $\theta_{\text {mean }}$ at all depths but $15 \mathrm{~cm}$.

\subsection{Topographic influences}

Regardless of soil depth, no significant Spearman correlation coefficient was found between the strength (i.e. $R_{\alpha}^{2}$ ) of the identified point-scale relationships and the values of any surface or subsurface terrain attribute. Nonparametric Kruskal-Wallis tests showed that the nature of the mathematical model chosen to illustrate the relationship between pointscale soil moisture contents and surrogate measures was seldom controlled by topographic variables (Tables 4 and 5). p-values reported in Table 4 indicate that elevation above the catchment outlet can be used to infer the nature of the point-scale relationships between soil moisture and $\mathrm{DSP}_{20}$. Figure 8 shows that at depths of 15,30 and $45 \mathrm{~cm}$, relationships between $\mathrm{DSP}_{20}$ and point-scale soil moisture tend to be not significant or cubic at intermediate elevations above the catchment outlet $(\sim 20 \mathrm{~m})$ and rather logarithmic or logistic at high elevations above the outlet ( $>25 \mathrm{~m}$ ), especially in the most upstream part of the catchment (see Fig. 5). For surrogate measures such as $\mathrm{AP}_{1}, \mathrm{AP}_{5}, \theta_{\text {mean }}$ and $Q_{\mathrm{obs}}$, a clear influence of elevation above the catchment outlet on the pointscale relationships was not discernable. For $\theta_{\text {mean }}$, in particular, linear and nonlinear relationships expand across the whole range of elevation values (Fig. 8), thus making it difficult to discern any clear spatial pattern. As for the influence of surface elevation on the relationships between $Q_{\text {obs }}$ and point-scale soil moisture measurements, it is only perceptible at depths of 5 and $45 \mathrm{~cm}$ (Table 4, Fig. 8) given the relative location of cubic and exponential models. The influence of the surface compound topographic index (CTI) and the Flatness index of the surface and of the confining soil layer on the patterns of point-scale relationships between selected AMCs proxy variables $\left(\mathrm{AP}_{2}, \mathrm{AP}_{5}, \mathrm{DSP}\right)$ and soil moisture was also examined (Fig. 9). Even though some minor differences can be perceived in the nature of the point-scale relationships as a function of the values of the subsurface Flatness index (Fig. 9), these differences are not significant (refer to $\mathrm{p}$-values reported in Table 5). The same conclusion applies to the nature of the point-scale relationships as a function of CTI or the surface Flatness index (Fig. 9, Table 4).

\section{Discussion}

The simple exercise conducted in this paper yielded new insight into the spatial representativity of proxy variables for AMCs or catchment response. While the relationships between actual soil moisture and several surrogate variables do exhibit strong spatial patterns (see examples in Figs. 4, 5 and 6), some others show rather poor spatial organization, thus casting doubt on the use of a single surrogate to illustrate a catchment state of wetness. Reaching such a conclusion was only possible through the use of an exhaustive soil moisture dataset that covers nearly the entire set of hydrological conditions of the Hermine catchment (Table 2), except for the winter and early spring seasons. Even though the patterns illustrated in Figs. 4, 5 and 6 only portray the spatial distribution of statistical relationships between actual soil moisture measurements and surrogate indices, they may reveal critical hydrological information. Hence, we argue that the simple statistical analyses conducted in this paper give a better understanding of the spatial heterogeneity of hydrological patterns and processes in the Hermine catchment.

It is not surprising that the $10 \%$ of the near-surface catchment area subjected to the influence of PET are located on 
Table 4. Influence of catchment surface topography (rows) on the nature of the point-scale relationships between soil moisture content and various surrogates (columns). Reported p-values are significant and suggest that at least one relationship type is associated with a median value of the studied topographic variable that is significantly different from the others.

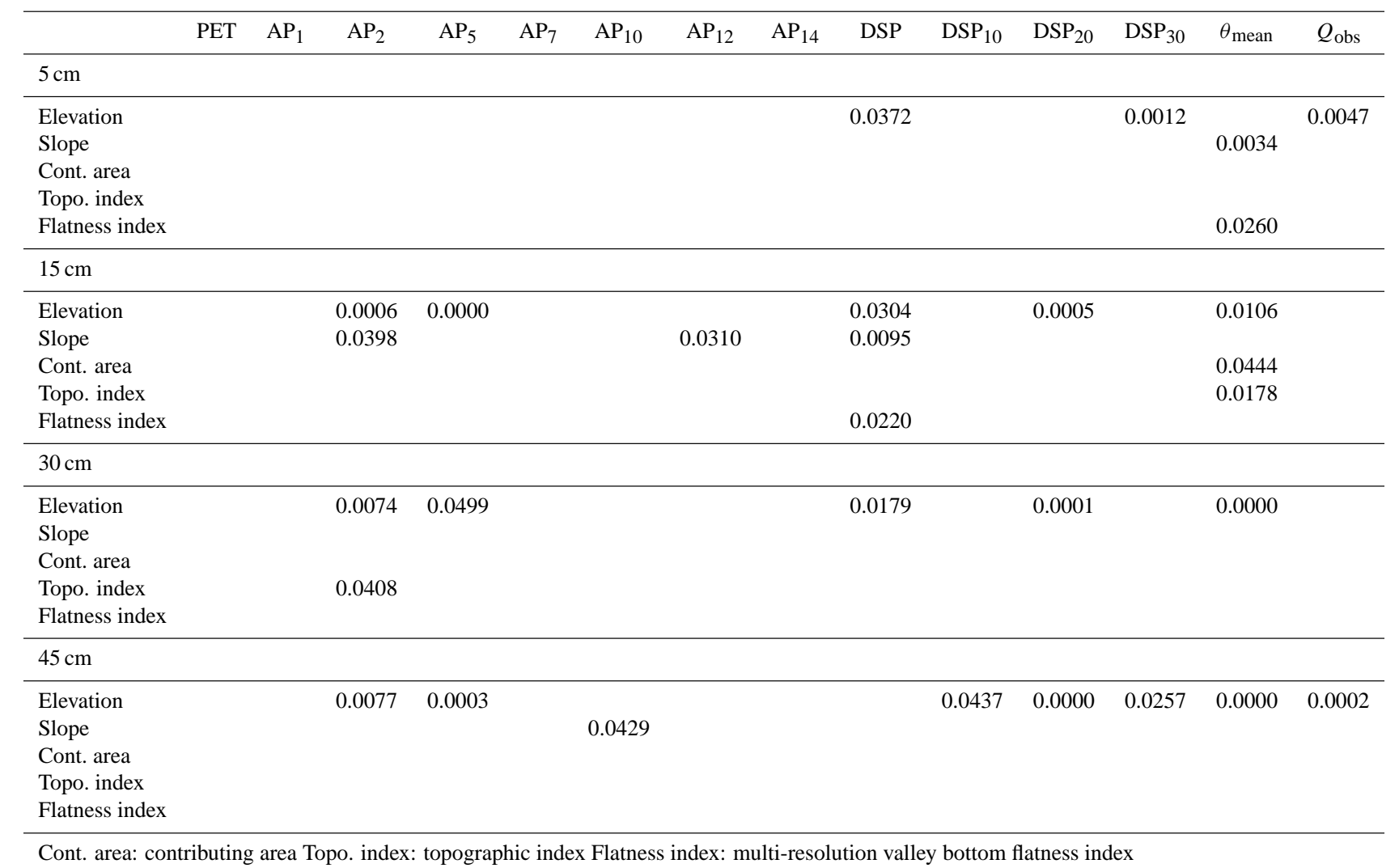

the upper parts of the southern slope, near the catchment divide and in a few other zones (Fig. 5) where canopy density is lower. On much of the Hermine catchment area, especially near the catchment head and on the northern slope, shallow soil moisture seems to be dominantly controlled by $\mathrm{AP}_{2}$ and $\mathrm{AP}_{5}$ (Fig. 4). Statistically significant, even though weak, relations between soil moisture measurements and $\mathrm{AP}_{12}$ (Fig. 4) suggest that soil wetness is not persistent in the long-term except for a small portion of the catchment corresponding to a low-elevation wet zone and to thin soils developed over a bedrock outcrop. Linear relationships between point-scale soil moisture and $\mathrm{AP}_{1}, \mathrm{AP}_{2}$ and $\mathrm{AP}_{5}$ are mostly present at $5 \mathrm{~cm}$ but regardless of the soil depth considered, they are outnumbered by nonlinear polynomial (i.e. quadratic and cubic) and exponential relationships (Fig. 4). This may be linked to the fact that the soil storage capacity is a function of the amount and timing of precipitation in addition to evapotranspiration (Ritcey and $\mathrm{Wu}, 1999$ ), or simply to the transmissivity mechanisms governing the vertical drainage of water in the soil.

Locations for which soil moisture is strongly related with catchment discharge may be indicative of catchment areas where triggering conditions for stormflow initiation are met. In that respect, it is worth noting that at depths of 30 and $45 \mathrm{~cm}$, in particular, the spatial patterns of significant relationships between actual soil moisture measurements and $Q_{\text {obs }}$ resemble the spatial patterns of significant relationships between actual soil moisture and $\mathrm{AP}_{5}$ (Figs. 4 and 6). Our approach makes it possible to distinguish near-surface from deeper potential "contributing" areas. It is also interesting to compare locations subjected to cubic or exponential relationships with $Q_{\text {obs }}$ (Fig. 6) as the two mathematical models mainly differ by their rate of increase. We could argue that the particular locations of exponential relationships hint towards rapidly enhanced subsurface water fluxes leading to the catchment outlet following water inputs to the catchment. It would be reasonable to assume that locations subjected to exponential relationships with $Q_{\text {obs }}$ are associated with the absence of depressions to fill in the topography of the soilconfining layer interface. It would also be reasonable to set them in opposition to the other locations which may be subjected to a soil storage threshold to exceed before any lateral water fluxes can occur (Spence and Woo, 2003; Tromp-Van Meerveld and McDonnell, 2006b; Kusumastuti et al., 2007), 
Table 5. Influence of the soil confining layer topography (rows) on the nature of the point-scale relationships between soil moisture content and various surrogates (columns). Reported p-values are significant and suggest that at least one relationship type is associated with a median value of the studied topographic variable that is significantly different from the others.

\begin{tabular}{|c|c|c|c|c|c|c|c|c|c|c|c|c|c|c|}
\hline & PET & $\mathrm{AP}_{1}$ & $\mathrm{AP}_{2}$ & $\mathrm{AP}_{5}$ & $\mathrm{AP}_{7}$ & $\mathrm{AP}_{10}$ & $\mathrm{AP}_{12}$ & $\mathrm{AP}_{14}$ & DSP & $\mathrm{DSP}_{10}$ & $\mathrm{DSP}_{20}$ & $\mathrm{DSP}_{30}$ & $\theta_{\text {mean }}$ & $Q_{\text {obs }}$ \\
\hline \multicolumn{15}{|l|}{$5 \mathrm{~cm}$} \\
\hline \multirow{2}{*}{\multicolumn{15}{|c|}{$\begin{array}{l}\text { Depth to layer } \\
\text { Slope }\end{array}$}} \\
\hline & & & & & & & & & & & & & & \\
\hline Cont. area & & & & 0.0433 & & & & & & & & & & \\
\hline Topo. index & & & & & & & & & & & & & & 0.0336 \\
\hline Flatness index & & & & & & & & & & & & & 0.0105 & 0.0482 \\
\hline \multicolumn{15}{|l|}{$15 \mathrm{~cm}$} \\
\hline Depth to layer & & & & & & & & & & & 0.0062 & & 0.0311 & \\
\hline Slope & & & & & & & & 0.0427 & & & & & & \\
\hline \multicolumn{15}{|l|}{ Cont. area } \\
\hline Topo. index & & & & & & & & & & & 0.0345 & & & \\
\hline \multicolumn{15}{|l|}{ Flatness index } \\
\hline \multicolumn{15}{|l|}{$30 \mathrm{~cm}$} \\
\hline \multirow{2}{*}{\multicolumn{15}{|c|}{$\begin{array}{l}\text { Depth to layer } \\
\text { Slope }\end{array}$}} \\
\hline & & & & & & & & & & & & & & \\
\hline \multicolumn{15}{|l|}{ Cont. area } \\
\hline Topo. index & & & & & & & & & & & & & & 0.0206 \\
\hline \multicolumn{15}{|l|}{ Flatness index } \\
\hline \multicolumn{15}{|l|}{$45 \mathrm{~cm}$} \\
\hline \multicolumn{15}{|l|}{$\begin{array}{l}\text { Depth to layer } \\
\text { Slope }\end{array}$} \\
\hline Cont. area & & & & & & & & & & & & 0.0442 & & \\
\hline Topo. index & & & & & & & & & & & & & & \\
\hline Flatness index & & & & & & & & & & & & & & \\
\hline
\end{tabular}

hence the slower increasing, cubic relationships with $Q_{\text {obs }}$. Even though plausible, this hypothesis is not confirmed by the Kruskal-Wallis tests results in Tables 4 and 5. In fact, there are no statistically significant differences in subsurface terrain attributes between locations sharing exponential relationships with $Q_{\text {obs }}$ and locations sharing cubic relationships with $Q_{\text {obs }}$. This conclusion highlights the main drawback of the purely statistical approach with regards to hypothesis testing, as the obtained regression models may not necessarily reflect causal relationships. Hence, we can only formulate hypotheses that would have to be tested against additional field data. For instance, in order to confirm or infirm the influence of subsurface topographic features on the rate of increase of catchment discharge with respect to point-scale soil moisture, the fluctuations of water storage at the soilconfining layer interface could be investigated.

Concerning the results on $\theta_{\text {mean }}$, the important spatial extension of statistically significant relations with point-scale soil moisture content at all four depths indicates that it is a good surrogate for describing the catchment soil moisture macrostate. This is in accordance with the methodology of several previous studies (e.g. Thierfelder et al., 2003; Grant et al., 2004; James and Roulet, 2009) that relied on the use of the catchment mean shallow soil wetness for process un- derstanding or modeling purposes. We, however, found that the less shallow the soil depth considered, the more locations whose soil moisture measurements were nonlinearly related to $\theta_{\text {mean }}$ (Fig. 5). The identified relationships between $\theta_{\text {mean }}$ and surrogate measures for AMCs and between $\theta_{\text {mean }}$ and $Q_{\text {obs }}$ fell short of capturing the heterogeneity of the pointscale mechanisms. This result requires further investigation as to how representative the $\theta_{\text {mean }}$ really is over different catchment areas and with changing depths.

It must be stressed that the sole reliance on indices often used in catchment hydrology, namely $\mathrm{AP}_{7}$ and $\mathrm{AP}_{10}$, would have led us to rely on a surrogate measure that is not related to soil moisture measurements in the Hermine. Even though soil moisture proxies based on antecedent rainfall can give good results (e.g. Kohler and Lindsey, 1951; Longobardi et al., 2003), the choice of the antecedent temporal window is crucial. In our case, $\mathrm{AP}_{5}$ is the best index to use as a surrogate for $\mathrm{AMCs}$ in the Hermine catchment while $\mathrm{AP}_{1}$, $\mathrm{AP}_{2}$ and $\mathrm{AP}_{12}$ yield fairly good results. Kohler and Lindsey (1951) have argued that indices simply computed from the number of days since the last rain are "obviously insensitive and should not be used if accurate results are required" (p.2). This statement does not reflect the results obtained for the Hermine catchment, especially when not only the days since 

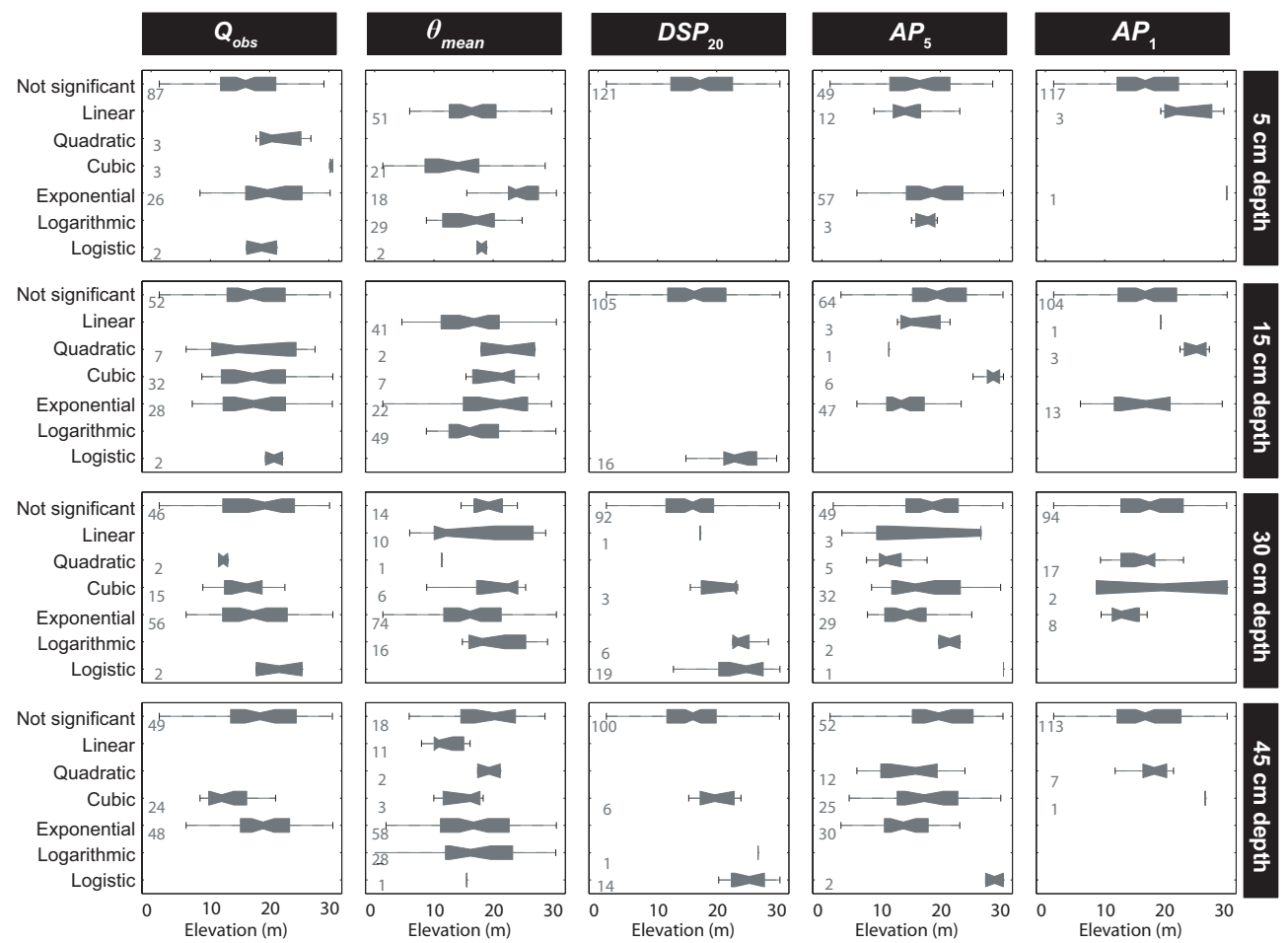

Fig. 8. Influence of surface topography (elevation above the catchment outlet) on the nature of the relationship between point-scale soil moisture (columns) and selected proxies for AMCs, catchment macrostate and catchment response (rows) in the Hermine. Grey numbers illustrate the number of data used to plot each box.

the last rain but also the rainfall intensity are considered. We suspect that Kohler and Lindsey's argument might be true in the large river basins with multiple tributaries as they refer to in their paper but not in a small headwater catchment like the Hermine. Statistically significant relationships were obtained between point-scale soil moisture measurements and DSP, $\mathrm{DSP}_{10}, \mathrm{DSP}_{20}$ and $\mathrm{DSP}_{30}$. For $\mathrm{DSP}_{20}$, a weak significant topographic control was even identified as logarithmic or logistic point-scale relationships with soil moisture were mostly present at high elevations above the catchment outlet ( $>25 \mathrm{~m}$ ) (Fig. 8). It is also worth mentioning that previousday discharges were also used as surrogates for AMCs (data not shown) but they were not involved in any significant relationship with point-scale soil moisture measurements; this result is contradictory to the affirmation of Kohler and Lindsey (1951) who argued that baseflow-derived indices provided reasonably good results in humid and sub-humid regions.

It is interesting to compare results obtained from previous studies in the Hermine catchment (Table 1) with the conclusions of the current paper. For instance, the same soil moisture content dataset was analyzed to characterize the emergence of spatially coherent saturation patches in the Hermine catchment (Ali et al., 2010a). The importance of $\mathrm{DSP}_{30}$, in particular, was then revealed: the smaller the surrogate measure for AMCs, the more likely the presence of 0.85-
1.4 ha wide saturation patches at a depth of $15 \mathrm{~cm}$ and the more likely the presence of saturation patches of less than 0.85 ha at a depth of $45 \mathrm{~cm}$. These conclusions are consistent with the patterns illustrated in Fig. 5. Furthermore, results from Ali et al. (2010a) corroborate the fact that relations between actual soil moisture and $\mathrm{AP}_{7}$ or $\mathrm{AP}_{14}$ are very rare and can only be perceived at the scale of very small saturation patches $(<0.1 \mathrm{ha})$. This comparison sheds light on the scale-dependent spatial representativity of AMCs surrogate measures. Ali et al. (2010a), however, did not identify any significant relations between soil moisture patterns and $\mathrm{AP}_{2}$, while it only captured the influence of $\mathrm{AP}_{5}$ on $0.54-0.85$ ha patches and the influence of $\mathrm{AP}_{12}$ on $0.02-0.1$ ha patches. These results are opposite with some of the $\mathrm{AP}_{2}$ patterns illustrated in Fig. 4 and the reason for this is unclear. Ali and Roy (2010d) also found that the spatial connectedness of locations whose volumetric soil moisture content exceeded $30 \%$ was dependent upon $\mathrm{AP}_{7}$. The relationship between connectivity and $\mathrm{AP}_{7}$ then had the form of a step function, which may explain why it was not captured by any of the tested regression models in the current paper. By stating that the relative contribution of geographic sources (i.e. organic versus mineral soil water originating from riparian or upslope areas) to streamflow are strongly correlated to $\mathrm{AP}_{2}$ and rather weakly correlated to $\mathrm{AP}_{7}$, Ali et al. (2010b) echo the conclusions of the present study about the appropriateness 

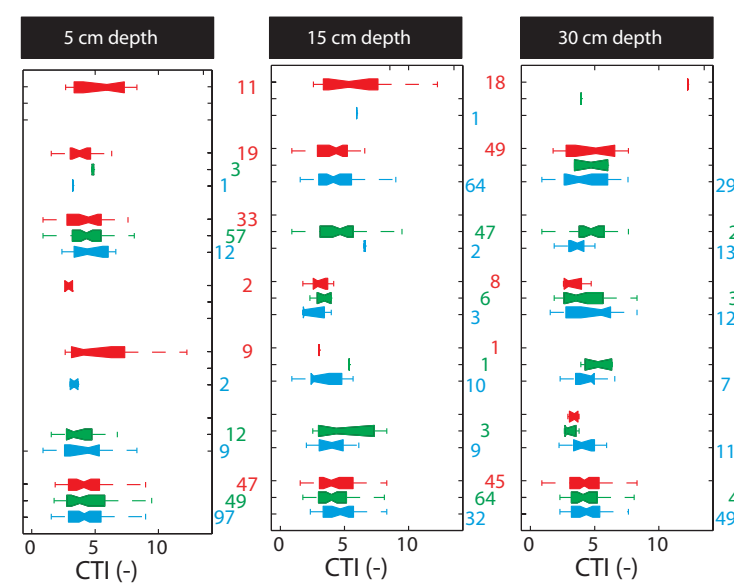

\section{$45 \mathrm{~cm}$ depth}
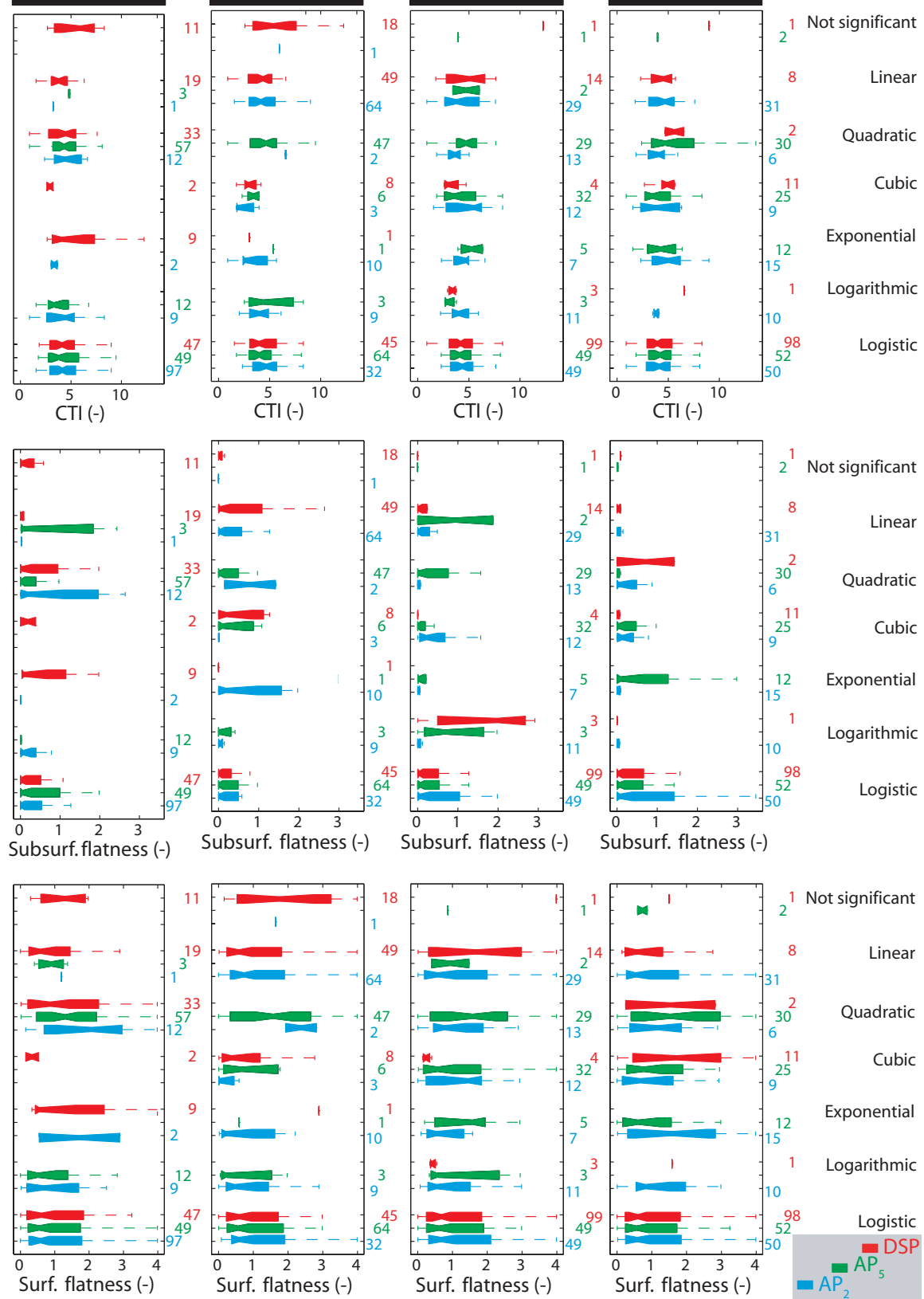

Fig. 9. Influence of various topographic properties (surface and subsurface multi-resolution valley bottom flatness and compound topographic index) on the nature of the relationship between point-scale soil moisture and selected surrogate measures for AMCs. Blue, green and red numbers illustrate the number of data used to plot each box of the same color.

of $\mathrm{AP}_{2}$ as a proxy for the Hermine catchment AMCs and the insignificance of $\mathrm{AP}_{7}$ in that regard. On the contrary to the current paper, Ali et al. (2010c) found that $\mathrm{AP}_{10}$ had an influence on the catchment behaviour only when the cumulative antecedent rainfall amounts lay in the range of 24.5 to $40.5 \mathrm{~mm}$. There again, such a relationship between catchment discharge and $\mathrm{AP}_{10}$ can be schematized as a rectangular function that does not bear any resemblance with any of the regression models tested in this paper. Hence, these results highlight the sensitivity of the results to the nature of the relations and of the ensuing regression model that is used.

Our results are catchment specific. They pertain to a small forested watershed with relatively steep slopes in a temperate humid climate. The small scale of the headwater basin and its relief may play a role on the optimal antecedent temporal window size that has been identified (i.e. 5 days) through 
the analysis. The approach, however, has a general value as the simple analysis described in this paper can be repeated for several catchments under various climatic regimes and for which spatially-detailed soil moisture data are available. This will allow the hydrological community to compare findings and maybe derive guidelines regarding the choice of proxy measures of AMCs in catchments with specific climatic and topographic characteristics. Lastly, it is worth mentioning that the rationale behind our statistical analysis comes from several studies that have described soil moisture as a major control of catchment response and an indicator of the location of active subsurface flow paths (e.g. Grayson et al., 1997; Meyles et al., 2003; Western et al., 2004; Western et al., 2005). However, while Van Meerveld and McDonnell (2005) have also agreed that soil moisture may co-vary with streamflow, they have rather identified transient saturation at the soil-bedrock interface or near a soil layer of reduced permeability to be a real trigger for lateral subsurface stormflow. This was latter confirmed with the fill and spill hypothesis (Tromp-Van Meerveld and McDonnell, 2006b). Tromp-Van Meerveld and McDonnell (2006c) also showed that in catchments such as the Panola study site (Georgia, USA), pre-event soil moisture variations were not the main control on the distribution of subsurface saturation during winter storms. The hypothesis according to which shallow soil moisture is a passive signal of transient saturation at the soil-confining layer interface in the Hermine catchment should therefore be verified in order to shed light on the patterns illustrated in Figs. 4, 5 and 6.

\section{Conclusions}

This paper aimed at determining whether or not multiple surrogates for AMCs had to be used in order to describe the moisture conditions within a catchment. With regards to the Hermine catchment, the answer to that question is affirmative. Without making any assumption on active processes, we computed the point-scale temporal relations between actual soil moisture measurements and commonly used meteorological-based indices so as to identify the surrogates for AMCs that are best suited to the Hermine catchment. Two principal results stood out. Firstly, it was shown that the sole reference to AMCs indices often used in catchment hydrology (i.e. $\mathrm{AP}_{7}$ or $\mathrm{AP}_{10}$ ) does not help predicting the catchment moisture conditions when linear, quadratic, cubic, exponential, logarithmic or logistic relationships are considered. Secondly, the relationships between point-scale soil moisture measurements and surrogates for AMCs were not spatially homogeneous, thus revealing a mosaic of linear and nonlinear catchment "active" and "contributing" sources whose location was seldom controlled by surface terrain attributes or the topography of the soil-confining layer interface. These results represent a step forward for the Hermine catchment as they point towards depth-specific pro- cesses and spatially-variable triggering conditions that are not controlled by topography. Such hydrological behaviour may also exist in other catchments. The analysis also raises several questions on the use of surrogate AMCs measures and on the generalization of results obtained with a single surrogate. Further investigations are, however, necessary to establish robust, causal relationships between soil moisture and meteorological-based proxies for AMCs and then derive guidelines concerning the best surrogate choice.

Acknowledgements. We gratefully acknowledge fellowship support awarded by the Natural Sciences and Engineering Research Council of Canada (NSERC) and the Fonds québécois de la recherche sur la nature et les technologies (FQRNT) to the first author. The research was also funded by the FQRNT. We thank the staff of the Station de biologie des Laurentides de l'Université de Montréal, Marie-Claude Turmel for her insightful suggestions towards the planning of the soil moisture surveys, and Marius Dulgheru, Gabi Chiaburu, Julie Thérien, Marie Lambois and Claude Gibeault for their occasional help on the field. We heartily thank our field assistants Rachel Thériault and Katherine Sicotte, who were able to take over the organization of the surveys when needed and contributed great effort in data collection. This study is part of the research program of the Canada Research Chair in fluvial dynamics.

Edited by: B. Schaefli

\section{References}

Akaike, H.: A new look at the statistical model identification, IEEE Transactions on Automatic Control, 19, 716-723, 1974.

Ali, G. A. and Roy, A. G.: Shopping for Hydrologically Representative Connectivity Metrics in a Humid Temperate Forested Catchment, Wat. Resour. Res., accepted, 2010d.

Ali, G. A., Roy, A. G., and Legendre, P.: Spatial Relationships between Soil Moisture Patterns and Topographic Variables at Multiple Scales in a Humid Temperate Forested Catchment, Wat. Resour. Res., in press, 2010a.

Ali, G. A., Roy, A. G., Turmel, M.-C., and Courchesne, F.: Source-to-Stream Connectivity Assessment through Endmember Mixing Analysis, J. Hydrol., 392(3-4), 119-135, doi:10.1016/j.jhydrol.2010.07.049, 2010b.

Ali, G. A., Roy, A. G., Turmel, M.-C., and Courchesne, F.: Multivariate analysis as a tool to infer hydrologic response types and controlling variables in a humid temperate catchment, Hydrol. Proc., 24(20), 2912-2923, doi:10.1002/hyp.7705, 2010c.

Ambroise, B.: Variable, "active" Versus "contributing" Areas or Periods: a Necessary Distinction, Hydrol. Proc., 18, 1149-1155, 2004.

Aryal, S. K., Mein, R. G., and O'Loughlin, E. M.: The Concept of Effective Length in Hillslopes: Assessing the Influence of Climate and Topography on the Contributing Areas of Catchments, Hydrol. Proc., 17, 131-151, 2003.

Betson, R. P.: What is watershed runoff?, J. Geophys. Res., 69, 1541-1552, 1964.

Beven, K. J. and Kirkby, M. J.: A physically based variable contributive area model of basin hydrology, Hydrol. Sci. Bull., 24, 43-69, 1979. 
Biron, P. M., Roy, A. G., Courchesne, F., Hendershot, W. H., Cote, B., and Fyles, J.: The Effects of Antecedent Moisture Conditions on the Relationship of Hydrology to Hydrochemistry in a Small Forested Watershed, Hydrol. Proc., 13, 1541-1555, 1999.

Bracken, L. J. and Croke, J.: The Concept of Hydrological Connectivity and Its Contribution to Understanding Runoff-Dominated Geomorphic Systems, Hydrol. Proc., 21, 1749-1763, 2007.

Brocca, L., Melone, F., and Moramarco, T.: On the estimation of antecedent wetness conditions in rainfall-runoff modelling, Hydrol. Proc., 22, 629-642, 2008.

Buttle, J. M., Hazlett, P. W., Murray, C. D., Creed, I. F., Jeffries, D. S., and Semkin, R.: Prediction of Groundwater Characteristics in Forested and Harvested Basins During Spring Snowmelt Using a Topographic Index, Hydrol. Proc., 15, 3389-3407, 2001.

Buttle, J. M. and Peters, D. L.: Inferring Hydrological Processes in a Temperate Basin Using Isotopic and Geochemical Hydrograph Separation: a Re-Evaluation, Hydrol. Proc., 11, 557-573, 1997.

Burnham, K. P. and D. R. Anderson: Model Selection and Multimodel Inference: A Practical Information-Theoretic Approach, 2nd ed., Springer-Verlag, New York, USA, 2002.

Cappus, P.: Étude des lois de l'écoulement. Application au calcul et à la prévision des débits, La houille blanche, A, 493-518, 1960.

Dunne, T. and Black, R. D.: Partial Area Contributions to Storm Runoff in a Small New England Watershed, Wat. Resour. Res., 6, 1296-1311, 1970.

Frot, E. and van Wesemael, B.: Predicting runoff from semi-arid hillslopes as source areas for water harvesting in the Sierra de Gador, southeast Spain, Catena, 79, 83-92, 2009.

Gallant, J. C. and Dowling, T. I.: A Multiresolution Index of Valley Bottom Flatness for Mapping Depositional Areas, Wat. Resour. Res., 39(12), 1347, doi:10.1029/2002WR001426, 2003.

Grant, L., Seyfried, M., and McNamara, J.: Spatial Variation and Temporal Stability of Soil Water in a Snow-Dominated, Mountain Catchment, Hydrol. Proc., 18, 3493-3511, 2004.

Grayson, R. B., Western, A. W., Chiew, F. H. S., and Blöschl, G.: Preferred States in Spatial Soil Moisture Patterns: Local and Nonlocal Controls, Wat. Resour. Res., 33, 2897-2908, 1997.

Hargreaves, G. H.: Moisture availability and crop production, Trans. ASAE, 18, 980-984, 1975.

Hewlett, J. D., and Hibbert, A. R.: Factors affecting the response of small watersheds to precipitation in humid areas, in: Proceedings of the International Symposium on Forest Hydrology, Pergamon, New York, 275-290, 1967.

Inamdar, S. P. and Mitchell, M. J.: Contributions of Riparian and Hillslope Waters to Storm Runoff Across Multiple Catchments and Storm Events in a Glaciated Forested Watershed, J. Hydrol., 341, 116-130, 2007.

James, A. L. and Roulet, N. T.: Investigating Hydrologic Connectivity and Its Association With Threshold Change in Runoff Response in a Temperate Forested Watershed, Hydrol. Proc., 21, 3391-3408, 2007.

James, A. L. and Roulet, N. T.: Antecedent moisture conditions and catchment morphology as controls on spatial patterns of runoff generation in small forest catchments, J. Hydrol., 377, 351-366, 2009.

Kirchner, J. W.: A Double Paradox in Catchment Hydrology and Geochemistry, Hydrol. Proc., 17, 871-874, 2003.

Kohler, M. A. and Lindsey, R. K.: Predicting the runoff from storm rainfall, Weather Bureau, US Dept of Commerce, Research Paper
No. 34, Washington, 1951.

Kusumastuti, D. I., Struthers, I., Sivapalan, M., and Reynolds, D. A.: Threshold Effects in Catchment Storm Response and the Occurrence and Magnitude of Flood Events: Implications for Flood Frequency, Hydrol. Earth Syst. Sci., 11, 1515-1528, 2007, http://www.hydrol-earth-syst-sci.net/11/1515/2007/.

Legendre, P. and L. Legendre: Numerical Ecology, 2nd English edition, Elsevier Science BV, Amsterdam, 1998.

Longobardi, A., Villani, P., Grayson, R. B., and Western, A. W.: On the relationship between runoff coefficient and catchment initial conditions, in: Proceedings of MODSIM 2003867-872, 2003.

Meyles, E., A. Williams, L. Ternan, and J. Dowd: Runoff Generation in Relation to Soil Moisture Patterns in a Small Dartmoor Catchment, Southwest England, Hydrological Processes, 17, 251-264, 2003.

Mishra, S. K., Jain, M. K., Pandey, R. P., and Singh, V. P.: Catchment area-based evaluation of the AMC-dependent SCS-CNbased rainfall-runoff models, Hydrol. Proc., 19, 2701-2718, 2005.

Noguchi, S., Tsuboyama, Y., Sidle, R. C., and Hosoda, I.: Subsurface Runoff Characteristics From a Forest Hillslope Soil Profile Including Macropores, Hitachi Ohta, Japan, Hydrol. Proc., 15, 2131-2149, 2001

Pearce, A. J.: Streamflow Generation Processes - an Austral View, Wat. Resour. Res., 26, 3037-3047, 1990.

Rice, K. C. and Hornberger, G. M.: Comparison of Hydrochemical Tracers to Estimate Source Contributions to Peak Flow in a Small, Forested, Headwater Catchment, Wat. Resour. Res., 34, 1755-1766, 1998.

Ritcey, A. C. and Wu, Y. S.: Evaluation of the effect of future climate change on the distribution and movement of moisture in the unsaturated zone at Yucca Mountain, NV, J. Contam. Hydrol., 38, 257-279, 1999.

Salvadori, G. and De Michele, C.: Statistical characterization of temporal structure of storms, Adv. Wat. Resour., 29, 827-842, 2006.

SCS: Hydrology. National Engineering Handbook, Supplement A, Section 4, Chapter 10, Soil Conservation Service, USDA, Washington, DC, 1956.

Seeger, M., Errea, M. P., Begueria, S., Arnaez, J., Marti, C., and Garcia-Ruiz, J. M.: Catchment Soil Moisture and Rainfall Characteristics as Determinant Factors for Discharge/Suspended Sediment Hysteretic Loops in a Small Headwater Catchment in the Spanish Pyrenees, J. Hydrol., 288, 299-311, 2004.

Sidle, R. C., Tsuboyama, Y., Noguchi, S., Hosoda, I., Fujieda, M., and Shimizu, T.: Seasonal Hydrologic Response at Various Spatial Scales in a Small Forested Catchment, Hitachi-Ohta, Japan, J. Hydrol., 168, 227-250, 1995.

Silveira, L., Charbonnier, F., and Genta, J. L.: The antecedent soil moisture condition of the curve number procedure, Hydrolog. Sci. J., 45, 3-12, 2000.

Sklash, M. G. and Farvolden, R. N.: The role of groundwater in storm runoff, J. Hydrol., 43, 45-65, 1979.

Spence, C. and Woo, M. K.: Hydrology of Subarctic Canadian Shield: Soil-Filled Valleys, J. Hydrol., 279, 151-166, 2003.

Tarboton, D. G.: A New Method for the Determination of Flow Directions and Upslope Areas in Grid Digital Elevation Models, Wat. Resour. Res., 33, 309-319, 1997.

Thierfelder, T. K., Grayson, R. B., Von Rosen, D., and Western, 
A. W.: Inferring the Location of Catchment Characteristic Soil Moisture Monitoring Sites. Covariance Structures in the Temporal Domain, J. Hydrol., 280, 13-32, 2003.

Tromp-Van Meerveld, H. J. and McDonnell, J. J.: Threshold Relations in Subsurface Stormflow: 1. A 147-Storm Analysis of the Panola Hillslope, Wat. Resour. Res., 42, W02410, doi:10.1029/2004WR003778, 2006a.

Tromp-Van Meerveld, H. J. and McDonnell, J. J.: Threshold Relations in Subsurface Stormflow: 2. The Fill and Spill Hypothesis, Wat. Resour. Res., 42, W02411, doi:10.1029/2004WR003800, 2006b.

Tromp-Van Meerveld, H. J. and J. J. McDonnell: On the Interrelations Between Topography, Soil Depth, Soil Moisture, Transpiration Rates and Species Distribution at the Hillslope Scale, Adv. Water Resour., 29, 293-310, 2006c.

Van Meerveld, I. T. and McDonnell, J. J.: Comment to Spatial Correlation of Soil Moisture in Small Catchments and Its Relationship to Dominant Spatial Hydrolological Processes, J. Hydrol., 286, 113-134, J. Hydrol., 303, 307-312, 2005.
Vidon, P., Hubbard, L. E., and Soyeux, E.: Seasonal solute dynamics across land uses during storms in glaciated landscape of the US Midwest, J. Hydrol., 376, 34-47, 2009.

Western, A. W., Zhou, S. L., Grayson, R. B., McMahon, T. A., Blöschl, G., and Wilson, D. J.: Spatial Correlation of Soil Moisture in Small Catchments and Its Relationship to Dominant Spatial Hydrological Processes, J. Hydrol., 286, 113-134, 2004.

Western, A. W., S. L. Zhou, R. B. Grayson, T. A. McMahon, G. Blöschl, and D. J. Wilson: Reply to Comment by Tromp Van Meerveld and McDonnell on Spatial Correlation of Soil Moisture in Small Catchments and Its Relationship to Dominant Spatial Hydrological Processes, J. Hydrol., 303, 313-315, 2005.

Wipkey, R. Z. and Kirkby, M. J.: Flow within the soil, Hillslope Hydrology, John Wiley and Sons, Ltd, New York, 1978.

Woods, R. and Rowe, L.: The changing spatial variability of subsurface flow across a hillside, J. Hydrol. N. Z., 35, 51-86, 1996.

Young, P. C. and K. J. Beven: Data-based mechanistic modelling and the rainfall-flow nonlinearity, Environmetrics, 5, 335-363, 1994. 